Article

\title{
Advancing the Industrial Sectors Participation in Demand Response within National Electricity Grids
}

\author{
Alexander Brem ${ }^{1,2,3, * \mathbb{D}}$, Dominic T. J. O'Sullivan ${ }^{2} \mathbb{D}$ and Ken Bruton ${ }^{2} \mathbb{D}$ \\ 1 Department of Mechanical, Biomedical and Manufacturing Engineering, Munster Technological University, \\ T12 P928 Cork, Ireland \\ 2 Intelligent Efficiency Research Group (IERG), Department of Civil and Environmental Engineering, \\ University College Cork, T12 K8AF Cork, Ireland; dominic.osullivan@ucc.ie (D.T.J.O.); \\ ken.bruton@ucc.ie (K.B.) \\ 3 DePuy Ireland Unlimited Company, Loughbeg, P43 NP38 Cork, Ireland \\ * Correspondence: alexander.brem@mycit.ie
}

Citation: Brem, A.; O'Sullivan, D.T.J.; Bruton, K. Advancing the Industrial Sectors Participation in Demand Response within National Electricity Grids. Energies 2021, 14, 8261 . https://doi.org/10.3390/en14248261

Academic Editor: Abu-Siada Ahmed

Received: 3 November 2021

Accepted: 2 December 2021

Published: 8 December 2021

Publisher's Note: MDPI stays neutral with regard to jurisdictional claims in published maps and institutional affiliations.

Copyright: () 2021 by the authors. Licensee MDPI, Basel, Switzerland. This article is an open access article distributed under the terms and conditions of the Creative Commons Attribution (CC BY) license (https:// creativecommons.org/licenses/by/ $4.0 /)$.

\begin{abstract}
Increasing the level and diversifying the sources of flexible capacity available to transmission system operators will be a pivotal factor for maintaining reliable control of national electricity grids. These response capacities are widely available; however, one area with large capacities that could benefit from advancements is the industrial sector. This sector's highly regulated nature ensures that structured procedures and thorough investigations are required to implement significant change. This study presents a systematic methodology to effectively categorise assets and evaluate their perceived risk of participation in demand response, allowing industries to present a sustainable portfolio of flexible capacity to the grid. Following implementation on an internationally relevant industrial site, this methodology identified several assets for participation, determining that it is realistic to expect 35 to $75 \mathrm{~kW}$ of flexible capacity from only air handling units on a single site. A selected unit was further evaluated using an internal air-temperature modelling tool. This demonstrated its ability to respond safely to the actual 2019 and 2020 grid frequency events and even remain off, at no risk to the indoor thermal environment for at least $20 \mathrm{~min}$ in each case. The potential impact of advancing industrial participation is presented, with the highest scenario providing almost $15 \mathrm{MW}$ of flexible capacity to the Irish national grid. The financial benefit achievable on a site from the most conservative assets was found to be between EUR 993 and EUR 2129 annually for a single response category and up to EUR 6563 based on payment multipliers. Overall, this research demonstrates the significant flexible capacities available within the industrial sector and illustrates the low-risk capabilities and considerable benefits achievable on a single site and for the wider national electricity grids with this concept.
\end{abstract}

Keywords: smart grid; demand response; industrial sector; flexible capacity; electricity market participation; demand side management; distributed energy resources; risk assessment

\section{Introduction}

The Irish electricity grid represents a clear and highly representative example of a national electricity grid that is significantly influenced by renewable energy sources (RESs), with these making up the second largest source of electricity after natural gas [1]. Wind generation is the main source of renewable electricity generated in Ireland, accounting for a normalised figure of $31.3 \%$ of all electricity generated in 2019 [2]. As wind is a particularly volatile, largely unpredictable and mostly non-dispatchable source of nonsynchronous energy [3], it can have a destabilising effect on the grid and increase its requirement in relation to the available flexible capacity. The Integrated Single Electricity Market (I-SEM) is the wholesale electricity market arrangement for the Island of Ireland [4]. EirGrid in the Republic of Ireland and the System Operator for Northern Ireland (SONI) are the transmission system operators (TSOs) responsible for maintaining the instantaneous 
balance of supply and demand [4]. The intended operating frequency of the Irish national grid is $50 \mathrm{~Hz}$, which is often used as an indicator of the health of the grid, as any imbalance between supply and demand will cause it to fluctuate from its perfectly balanced $50 \mathrm{~Hz}$ frequency [5]. The normal operating range is between 49.8 and $50.2 \mathrm{~Hz}$, but excursions outside these bounds can occur if there are sudden changes in system demand, generation or interconnector flow [5]. It is essential that TSOs maintain equilibrium as significant fluctuations can damage power systems or in extreme cases lead to blackouts. This is particularly relevant and topical in Ireland at present, as there is considerable unease around the adequacy of supply, especially over the winter months, emphasised by two significant gas power stations being offline for repairs, making it more difficult for the TSOs to ensure reliable operation [6]. There are many factors enabling the TSOs to maintain reliable grid operations, with one important aspect being captured under the "Delivering a Secure, Sustainable Electricity System" (DS3) programme [7]. The underlying objective of this programme is to allow the TSOs to safely manage the grid at 75\% system non-synchronous penetration (SNSP) [8]. The SNSP limit defines the percentage of the generation mix that can be made up of RESs, interconnector capacity or other non-synchronous generation sources at any time. A 75\% SNSP limit means that, at any given time, the TSOs can maintain reliable operation with $75 \%$ of supply coming from variable sources, for example, from wind generation [8]. A vital aspect of this is achieved through offering several incentivised system services under various reserve, ramping, inertia, fast response and reactive power categories [9].

In a rapidly changing climate and energy sector, decision makers are constantly challenged to adapt and innovate to meet emissions and efficiency targets. The continued integration of distributed energy resources (DERs), the proliferation of RESs and the increased impact of alternative fuel vehicles [10] on electricity grids worldwide ensures that TSOs must keep pace with developments [11]. As a result, the number of demand response (DR) and demand-side management (DSM) programmes and participants to assist the TSOs to maintain the instantaneous balance is increasing year upon year. The smart grid is a fluid concept with considerable development potential worldwide, being driven by a number of key factors. The transition from conventional, large fossil-fuelpowered generation plants towards more dispersed and variable RESs to meet emissions targets is having a two-fold impact [3], particularly on the Irish national grid. As the increase in RESs adds considerably more variability to the system, the continued retirement and decommissioning of fossil fuel plants is removing a historically stable and reliable source of generation $[12,13]$. As a result, stakeholders will have to adopt a more proactive, "prosumer" approach, in which energy is both produced and consumed onsite [3], and TSOs will have to ensure that a suitable flexible capacity is always readily available. System flexibility or flexible capacity is used to reduce the mismatch between power demand and supply [14]. This can be defined as aggregated electrical capacity at the TSO level, which is available to respond and provide system regulation and stabilisation without jeopardising the operational constraints of DERs or the source distribution networks [15]. The increase in demand-side units (DSUs) and DSM measures offering this flexibility will have to grow considerably from the $571 \mathrm{MW}$ of DSU capacity clearing the T-1 capacity market auction and the 620 MW capacity clearing the 2022/23 T-4 capacity auctions held in 2019 [12]. Large energy users will need to update or adapt their energy systems, encouraged by structured incentive schemes [16], to provide this increasingly valuable assistance to their national grids if the most optimistic 2030 target of $900 \mathrm{MW}$ and the 2040 target of $1000 \mathrm{MW}$ are to be achieved [13]. The Irish Large Industry Energy Network (LIEN) [17] offers considerable potential for advancements in this area, being a group of large industries that are already committed to collaborating to improve their energy performance and to operate at the cutting edge of sustainable energy developments. The LIEN represents nearly 200 of Ireland's largest energy users, accounting for $21 \%$ of the national total primary energy requirements in 2019 [17]. This annual percentage figure equates to 36,600 GWh, meaning 
any participation or flexible capacity figures from this group can provide considerable value on a national scale.

There is great potential for participation in smart grids and DSM programmes across all sectors around the world. Existing examples of individual or combined programmes can be seen throughout the residential, commercial and industrial sectors [18]. On the residential scale, there are examples of buildings providing flexible DR through smart control systems. In these scenarios, the building management system (BMS) is designed to follow a designated power set point from the grid operator and to signal the acceleration or postponement of its space heating loads accordingly [19]. Examples of large aggregations of residential participants also exist, with the most developed instance of this being community choice aggregations (CCAs). A CCA is generally a system in which a large group of residential energy users come together to form a single aggregated consumer and in areas where DERs such as rooftop solar photovoltaics are common, they can even become prosumers for the local grid [20]. In 2019, the average Irish dwelling consumed a total of $18,748 \mathrm{kWh}$ of energy annually, with $24 \%$ of this $(4544 \mathrm{kWh})$ being attributed to electricity [2]. As large-scale CCAs are yet to take off in Ireland, the instantaneous capacity potential of residential dwellings is currently too small to be seriously considered for market participation with current infrastructures and existing policies. In the commercial and industrial sectors, on the other hand, although uptake may be more reserved, there are many notable examples of participation in these programmes [21,22]. The industrial sector in particular is a prime candidate, as individual asset power consumption is generally higher [23]. This is often complimented with reduced installation costs where advanced metering infrastructure already exists, further supporting the case for engagement within the industrial sector. Naturally, certain critical assets or sensitive loads will remain outside the scope of inclusion, such as computer numerical control (CNC) machines, lathes and mills $[23,24]$. However, numerous ancillary services and utility assets could be suitable for $\mathrm{DR}$, such as air handling units (AHUs), large motors and even pumps serving non-processcritical areas. Each of these assets, among others, have the potential to be included in industrial flexible response portfolios, complimenting other large power-consuming assets to provide useful response capacities to the TSOs and achieve the benefits that accompany DR incentive schemes [25].

The actual quantity and value of flexible capacity available on industrial sites is yet to be fully understood and is certainly a long way from being fully utilised to provide the benefits of participation to national electricity grids [26]. Therefore, it is worth conducting thorough studies of all energy-using assets on an industrial site to evaluate their capabilities and the specific flexible capacities available. This will allow new participants and assets to engage in DR and provide flexible capacity for TSOs beyond the existing Irish examples of large motors and pumps in mining and quarrying applications [27] and high-consumption foundry loads in the metal industry [28], which are the largest and most suitable flexible capacity solutions that have already been captured. A defined evaluation methodology is required to ascertain asset flexibility, ensure reliability and to minimise any perceived risk of participation and advanced implementation. In the wider industrial sector, evaluations have demonstrated that small-to-medium-sized enterprises can be capable of offering approximately $36 \mathrm{~kW}$ of technical load-shifting potential [29]. However, that particular study of manufacturing sites was limited to only flexible production processes for load shifting and did not consider the potential to shutoff these assets or any of the other ancillary service units for DR. This demonstration illustrates some of the capabilities but not the full flexible resource potentially available if further assets were included in a response portfolio. Adding the required operations or updating an asset's secondary functions to allow them to participate in DR can have unforeseen effects on outputs or associated process stakeholders [30]. It is therefore important to fully investigate the impact of any changes to a process, further enforced by the validation culture present in the risk-averse and thoroughly standardised industrial sector [31]. A well-established practice for evaluating the impact of process changes is the Design of Experiments (DOE) 
methodology [32]. DOE is a popular technique for efficiently investigating the effect of varying inputs on experimental outputs with a structured and optimised approach [33]. This process can be universally beneficial but has shown particular prominence in the pharmaceutical [34] and medical [35] sectors due to its rigorous yet efficient evaluation of large quantities of data. The DOE approach can also be applied to the multi-variant analysis of manufacturing processes [36], electrical engineering control and modelling applications [32] and assessing the conditional risk metric for a mix of contracts on the energy market [34]. The demonstrated cross discipline success of this methodology ensures its rigor and integrity when assessing any effects of operational adjustments and accurately evaluating their impacts on industrial sites. This industry-proven element can be essential to successfully evaluating any risk associated with adapting an assets operation to unlock its ability to engage and participate in DSM programmes.

Deciding which assets are suitable for DR and ensuring the rigor of this selection is vital to guaranteeing the integrity and quality of each participant's engagement. Therefore, it is important to base each decision and assessment on robust industry best practices. The International Organisation for Standardisation (ISO) publishes and maintains one of the most prominent industry standards on the topic of risk assessments, entitled ISO 31000 Risk management-Guidelines [37], with associated additional information in ISO 31010 Risk management-Risk Assessment Techniques [38]. These documents provide the basis for managing risk faced by organisations at any stage of their lifecycle, similarly to the DOE methodology, ensuring that a standardised approach is maintained while addressing any form of risk. There is also consensus throughout industry that criticality ranking and assigning these thoroughly considered risk ratings to assets benefits decision making and further improves the reliability and the predictability of maintenance procedures $[39,40]$. These methodologies are particularly evident in large industries such as the petrochemical industry $[41,42]$ and the power sector $[43,44]$, where failures or inadequate maintenance can lead to catastrophic failures. The underlying principles can be applied to scheduling maintenance of smaller-scale industrial assets, whereas they can also be effectively transferred and implemented as a measure of an asset's suitability for DR participation. Furthermore, examples of load control concepts provided by existing large industries such as Siemens [45] and ABB [46] offer elements of network protection within the industrial sector. These systems reduce consumption or switch off certain assets to maintain network security on an individual site and prevent negative repercussions to the electricity network. Although these structures do not consider DR capabilities or any other valuable potential from these systems, they do present evidence that industrial assets can safely be used to respond to grid signal requirements. Building on these examples can help to identify clearly which assets may be suitable for DR and increase confidence in their abilities to participate safely.

Another valuable factor when evaluating an asset's potential for DR and DSM participation is modelling, more specifically, thermal environment modelling when it comes to AHU participation. This allows the potential user to evaluate any risk of inclusion early in the process, before any physical changes or practical trials are conducted. A number of studies have been conducted into modelling industrial asset performance, such as combined heat and power (CHP) units [47] and AHU loads to reduce peak power demands during peak times [48]. Further studies have been conducted in the commercial and residential sectors to assess the potential of AHUs participating in DR [49-51]. Each of the modelling approaches outlined in Table 1 were evaluated by the sector they are designed for, the software used, their accuracy where presented under either coefficient of determination $\left(R^{2}\right)$ or root mean squared error (RMSE) and whether they were designed to address DR potential and appropriately evaluate risks. The selected modelling approach has been shown to be the most suitable as it is the only approach designed for the industrial sector that satisfies each of the requirements, with an appropriate level of accuracy and an easily adopted framework within the Python environment. This systematic approach, combining elements of nodal networks and resistance $(R)$ and capacitance $(C)$ theories, was found to 
be the most suitable method of modelling any risks to indoor thermal environments on industrial sites participating in DR based on the building-type specifics and various other relevant influences [52]. This modelling process clearly demonstrates any potential risks on actual industrial sites participating in DR, which can be invaluable when included as part of a full risk assessment methodology.

Table 1. Comparison of the modelling approaches considered to conduct further risk assessment and analysis, with the selected approach highlighted in bold.

\begin{tabular}{cccccc}
\hline Model & Sector & Software & Accuracy & DR & Risk \\
\hline CHP [47] & Industrial & Matlab & $\mathrm{R}^{2}=0.94$ & - \\
AHU 1 [48] & Industrial & General Algebraic Modelling & - & - & - \\
AHU 2 [49] & Residential/Commercial & EnergyPlus & $\mathrm{R}^{2}=0.54-0.78$ and & $\mathrm{Y}$ & $\mathrm{Y}$ \\
AHU 3 [50] & Commercial & Dymola (Modelica) & RMSE $=0.48^{\circ} \mathrm{C}$ & $\mathrm{Y}$ & $\mathrm{Y}$ \\
AHU 4 [51] & Commercial & Simulink (Matlab) & - & $\mathrm{Y}$ & $\mathrm{Y}$ \\
Selected Approach [52] & Industrial & Python & RMSE $=0.3^{\circ} \mathrm{C}$ & $\mathrm{Y}$ & $\mathrm{Y}$ \\
\hline
\end{tabular}

\section{Proposed Contributions}

The objective of this research was to advance the industrial sector's engagement with and involvement in DR programmes and increase the flexible response capacity available to TSOs managing the national electricity grid. The aim is to achieve this by presenting a methodology to effectively categorise selected assets and evaluate their perceived risk of participation in a structured and standardised manner. This will allow the participant to present a sustainable portfolio of suitable response assets at an acceptable level of risk, including any additional mitigation measures as appropriate, to offer flexible capacity to the TSO, enabling them to benefit themselves and the national electricity grid. A further contribution of this research is the implementation of an internal air temperature model to further investigate and present the evaluation of any risks associated with industrial AHUs participating in DR schemes. A scenario analysis, assessing the financial benefit of participation for a single site and the potential impact of this concept on the national electricity grid at relevant scales are also presented as contributions of this research.

The remainder of this paper is broken down into four sections. The overall methodology, case study building and modelling approach are detailed in Section 2. The results of the implementation on the case study site, modelling and scaling scenarios are outlined in Section 3. Discussion of these results and the impact of this research are presented in Section 4. Concise conclusions are drawn and presented in Section 5, as well as potential avenues for future work based on this research.

\section{Materials and Methods}

\subsection{Methodology Overview}

The methodology and process steps required to select and evaluate assets to advance industrial participation in national electricity markets are outlined in Figure 1 . The first step in this process and the foundation of this methodology are largely based on the best practices demonstrated by the DOE process [32]. Step 1 includes defining the scope, brainstorming and discussion sessions and further project formalisation. To ensure the appropriateness of the stakeholder engagement and eliminate bias, these sessions are conducted through a semi-structured and silent brainstorming process, incorporating the affinity diagram technique to capture data and categorise outputs [53]. The key aspects to consider are whether all onsite energy-using assets will be considered or just nonproduction and utilities assets, if any existing onsite projects or procedures can be leveraged and if all DR system services will be targeted or only specific ones based on suitability. Additionally, the question of whether an external aggregator will be contacted should be considered and, if so, which one and how will this engagement be managed. Following 
this approach from the outset ensures that the user fully outlines the project and its scope and formalises the intended goals and final objectives in a systematic and well-defined manner. Engaging with all stakeholders and subject-matter experts throughout the process helps to gain a comprehensive understanding of the concept and all aspects involved throughout the process. To ensure the integrity and value of the stakeholder engagement for this work, it is important to ensure representation from at least the following rolestop-level management; a facilities, operations, production and maintenance technician; and a team-leader role from each of these departments. This ensures that high-level and very specific details are captured and considered from every perspective and department relevant the project. Additionally, building a rapport and maintaining communication with each of these stakeholders throughout the project helps to ensure the smooth and successful progress of the methodology.

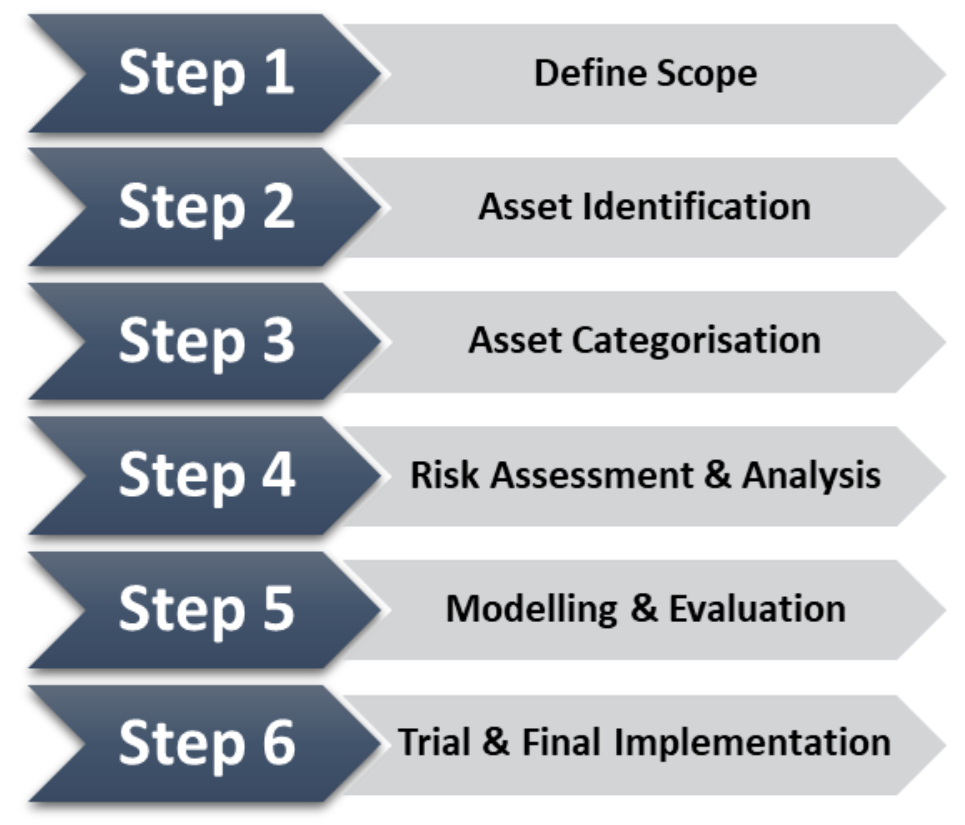

Figure 1. Overview of methodology process steps.

Step 2 is the major information-gathering stage, in which all applicable energy-using assets are identified and their relevant information is collected to ensure that the complete resource available on the site is captured. On an industrial site, this information is generally found through facilities or maintenance documentation, advanced metering systems and data historians or physical site walks, during which each asset's details, including system identification tags, description, location, nameplate capacity, transmission and distribution board connections and metering status, are collected and confirmed. This information is then compiled into an exhaustive asset register, containing all of the relevant energyconsuming asset information. This comprehensive asset register builds a strong foundation for the process, for which a greater level of detail and higher-quality inputs maximise its functionality. As key decisions will be based on this register, the accuracy of its information and quality of its data are important, ensuring that this quality will help to minimise issues and the time spent connecting assets and communication protocols for final implementation and eventual DR participation.

Once all applicable assets have been identified and compiled into the register, each asset is then categorised in Step 3. The assets are evaluated according to suitability criteria, including rated power capacity, ease of access and complexity or cost of inclusion, and then assigned a categorisation level, as outlined in Table 2 . These suitability criteria were developed as part of this study through engagement with a number of currently operating international DR aggregators, discussions with several specific asset and process subjectmatter experts and relevant prospective participants. The categorisation process effectively 
breaks down the entire portfolio of energy-using assets on the site into groups, ensuring that only the suitable assets progress through the remaining steps, minimising the amount of time spent on unsuitable assets. The detailed asset categorisation process, in addition to being a fundamental step in the methodology, also provides a structured roadmap for continual improvement and progression for the participating site. By maintaining an up-to-date version of this asset register, the user will always have a categorised list of assets available for DR participation. As assets progress up the levels, either through the asset being relocated, through the occurrence of significant process or standard operating procedure (SOP) changes or through capital becoming available to advance their suitability for inclusion, the register will capture this. By utilising the asset register, the user will always be aware of their current portfolio available for electricity market participation, allowing them to fully benefit from their aggregated flexible capacity and to maximise their performance.

Table 2. Description of asset categorisation levels for step 3 of the methodology.

\begin{tabular}{cc}
\hline Categorisation Level & Description \\
\hline 1 & Large reliable capacity, negligible to no impact on the end use and suitable access to warrant inclusion \\
2 & Meets all criteria but capacity not large enough to warrant inclusion at this time \\
3 & May be included once minor change to process/SOP, cost or location/complexity occurs \\
4 & Not included unless major change to process/SOP, cost or location/complexity occurs \\
\hline
\end{tabular}

Each of the assets categorised as level 1 are advanced for further in-depth risk assessment and analysis in Step 4. This evaluation consists of a number of risk assessment techniques, presented and endorsed by the ISO standards [38], namely, the risk priority number (RPN) technique, severity vs. probability (SvP) analysis and the bow tie (BT) analysis technique. These techniques have partially been adapted from a traditional focus on general risk to a more defined and specific scope of risk caused by inclusion and participation of the asset in DR. Drawing on established and industry-proven methodologies, the RPN criteria headings of Safety, Environment, Operational and Detectability were chosen to comprehensively evaluate each asset $[40,41]$. This ensured that each factor was fully considered under each of the specified headings, allowing its potential impacts to be quantified with a comparable and fully representative figure. An SvP matrix offers a structured means to evaluate and combine qualitative and semi-qualitative ratings of severity and the probability of occurrence to produce a quantitative risk rating [38]. The increasing scale helps to highlight significant risks and ensures that each rating is comparative regardless of asset or process specifics. A BT analysis provides a clear diagrammatic method of describing and analysing the extent of a risk from causation through to consequence, illustrating the complete lifecycle of the associated risks, prevention controls and mitigation measures [54]. Visually representing this analysis and highlighting each of the factors can be invaluable when engaging in discussions with stakeholders, as it helps to provide a clear and detailed overview of the study and particular asset in question. On completion of Step 4, it is possible to select assets for participation in electricity markets confidently based on the completed evaluation, illustration and analysis of the perceived risks associated with each asset's participation.

Step 5 consists of modelling the selected asset to further evaluate its applicability and demonstrate additional rigor around the low risk of its inclusion in a DR aggregation for electricity market participation. This step can also be viewed in isolation as a tool to verify the low risk levels of a selected asset, and in the case of an AHU can be seen as a modelling tool for indoor thermal environment risk assessment and mitigation. This step allows the user to evaluate the performance of an asset participating in DR schemes virtually and to scrutinise the low risk levels before any real-world implementation is conducted. This helps to build confidence in the selections and can further analyse additional assets to grow the aggregated capacity figure based on the scalable and easily transferrable nature 
of the model. At this stage, further analysis and relevant insights can be gained for future assets or onsite works that can positively benefit a site's ability to participate in future DR schemes.

The final step of the methodology, Step 6, encompasses the trial of assets, where necessary, and the final implementation and commitment to participation in DR and DSM schemes. This step takes the outcome of the methodology and risk assessment process to present a practical flexible capacity from the specific industrial site. This confidently selected aggregated capacity figure will have a level of risk acceptable to the participant and will be suitable for engagement with and participation in DR schemes within the national electricity grids.

\subsection{Case Study Building}

The case study industrial site selected for this research was a multi-national manufacturing plant located in county Cork, Ireland. This site manufactures medical devices across two industrial buildings containing a number of production, utilities and generation assets, including two wind turbines, two CHP generators, biomass boilers and a solar photovoltaic array. This site, built in 1997, was chosen as its processes and general construction offer a prime example and representation of the wider manufacturing and industrial sector. This site is certified to a number of esteemed industry standards, for example ISO 50001 and ISO 14001, to name a few, which demonstrate its established commitment to continual improvement and innovation, which is heavily ingrained throughout every aspect of the site. Having previously engaged in electricity market response schemes with its CHP plant, this site is perfectly placed to continue developments and advance its capabilities in this area. The main challenge and potential barrier to further electricity market participation is the validation requirements prevalent in the industrial sector and the rigor required to fully evaluate and mitigate any potential risk to optimal operation. Therefore, this site is an ideal candidate for the implementation of this methodology as the comprehensive evaluation and rigorous risk assessments are well suited to appraising the site's asset portfolio to identify suitable low-risk assets to include in DR schemes and further grow its available flexible response capacity. The active involvement of this site in industry collaborations in its locality, such as the Cork Lower Harbour Energy Group (CLHEG) or the wider national LIEN group, also offer considerable opportunities. Through collaboration and coordination of the available flexible response capacities there is potential to create a group response portfolio or even a virtual power plant, capable of offering large capacities and significant benefits to the national electricity grid.

\subsection{Preparation to Implement Modelling Tool}

To ensure that this methodology provided a comprehensive risk assessment and to further expand on Step 5-modelling and evaluation-the downstream risks of electricity market participation for selected assets had to be thoroughly evaluated. In the case of the AHUs, which were identified as the most common and lowest-risk asset for inclusion, a specialised evaluation or modelling tool was required. This concept of incorporating industrial AHUs into DR programmes and demonstrating any associated risks has not yet been thoroughly evaluated outside of this study and one other study [52]; this forms the basis of the modelling evaluation. This modelling tool allows the potential DR participant to base their decision to engage on the actual demonstrated performance of a comparable representative industrial AHU. To mitigate the challenges of field investigations on industrial sites, such as interacting with equipment outside of planned downtime, connecting to local networks or gaining access to firewall protected systems. An offline, simulation-based, systematic modelling approach was adopted to investigate the operational risks associated with office-based industrial AHUs participating in DR [52]. Using a mechanistic 1R1C air temperature model of a representative industrial building office space coupled with a simplified thermal energy model of an $\mathrm{AHU}$, the complete evaluation of any risk associated with its DR participation was achieved [52]. Taking the specific building details, materials 
and characteristics, as well as occupancy levels, operating schedules and the actual external air temperatures for the relevant site, it was possible to simulate and investigate the impact and any associated risk of its participation in grid frequency response events. This allowed any risks to the internal thermal environment to be easily identified, as any temperature deviations above or below the allowable limits during an AHU shutdown for DR are clearly illustrated in this process. The evaluation helps to reduce the perceived risk and, when risks do occur, allows mitigation measures to be put in place to minimise any further risk to stakeholders and end-users.

To evaluate the perceived risk of DR participation effectively, it was important to investigate actual grid frequency events that had already taken place under real-world conditions. A valuable aspect of this was collecting the actual grid frequency data from EirGrid for the two years prior to this study, 2019 and 2020 [5], to study when these grid events had previously occurred. By examining these data, it was possible to identify any time the grid frequency dropped below $49.7 \mathrm{~Hz}$, which signified a grid frequency event, as the frequency had fallen below the lower limit of its operating threshold [55]. By extracting these data, it was possible to isolate when these grid frequency events had previously taken place, with the examples occurring during the AHU operating hours outlined in Table 3. The remaining occasions and further examples of when the grid frequency dropped below $49.75 \mathrm{~Hz}$ can be found in Appendix A, Table A1. In each of these tables, the specific date, start time, duration below $49.75 \mathrm{~Hz}$ in seconds, trigger frequency initiating the event and frequency range throughout can be found.

Table 3. Overview of grid frequency events occurring in 2019 and 2020 during the AHU operating hours and the external temperature collected from the case study site on these days.

\begin{tabular}{|c|c|c|c|c|c|c|c|c|c|}
\hline $\begin{array}{c}\text { Date } \\
\text { (dd/mmm/yy) }\end{array}$ & $\begin{array}{l}\text { Start Time } \\
\text { (hh:mm:ss) }\end{array}$ & $\begin{array}{l}\text { Duration } \\
\text { (s) }\end{array}$ & $\begin{array}{c}\text { Trigger } \\
\text { Frequency } \\
(\mathrm{Hz})\end{array}$ & $\begin{array}{c}\text { Frequency } \\
\text { Range } \\
\text { (Hz) }\end{array}$ & $\begin{array}{l}\text { Tmin } \\
\left({ }^{\circ} \mathrm{C}\right)\end{array}$ & $\begin{array}{c}\text { Time } \\
\text { (hh:mm) }\end{array}$ & $\begin{array}{c}\text { Tmean } \\
\left({ }^{\circ} \mathrm{C}\right)\end{array}$ & $\underset{\left({ }^{\circ} \mathrm{C}\right)}{\operatorname{Tmax}}$ & $\begin{array}{c}\text { Time } \\
\text { (hh:mm) }\end{array}$ \\
\hline 3/March/2019 & $06: 12: 59$ & 111 & 49.703 & $49.662-49.749$ & 4.08 & $02: 45$ & 7.83 & 11.61 & $14: 45$ \\
\hline 20/March/2019 & $16: 46: 16$ & 4 & 49.672 & $49.574-49.706$ & 4.63 & 01:30 & 11.28 & 20.44 & $14: 30$ \\
\hline 24/April/2019 & $15: 21: 07$ & 5 & 49.702 & $49.608-49.711$ & 10.19 & $03: 15$ & 13.61 & 21.7 & $16: 00$ \\
\hline 8/May/2019 & 09:14:23 & 7 & 49.655 & $49.576-49.721$ & 6.88 & 04:30 & 10.34 & 16.55 & $12: 15$ \\
\hline 20/May/2019 & $14: 54: 12$ & 226 & 49.743 & $49.542-49.749$ & 8.26 & $23: 45$ & 13.22 & 21.38 & $18: 15$ \\
\hline 11/July/2019 & $07: 53: 37$ & 5 & 49.696 & $49.632-49.743$ & 12.51 & 01:00 & 16.50 & 22.08 & $11: 15$ \\
\hline 19/July/2020 & $06: 26: 35$ & 45 & 49.599 & $49.599-49.748$ & 6.63 & $23: 45$ & 16.82 & 30.7 & $16: 30$ \\
\hline 23/September/2020 & $11: 02: 15$ & 5 & 49.531 & $49.531-49.531$ & 9.48 & $23: 45$ & 13.21 & 18.12 & $15: 00$ \\
\hline
\end{tabular}

The zone being modelled and evaluated in this study is a large open-plan office space located on the case study manufacturing site. This office space was selected as a representation of similar office spaces throughout the industrial sector, which are found in buildings of which the primary function is manufacturing or process-based, and offices are included as a secondary function. This often results in the office spaces being located in buildings with lower internal heat capacities than commercial or purpose-built office blocks, making them more interesting from an AHU DR perspective. In this case, the building housing the office space was found to have a light internal effective heat capacity classification according to ISO 52016-1 [52], which is common within the industrial sector. The particular AHU serving this area operates on a regular Monday-to-Friday schedule for normal occupancy and working hours. It is monitored and controlled from a central BMS, where the internal, external and numerous other system temperatures can be viewed, as well as a number of other operational parameters. This industrial AHU would be able to offer approximately $15 \mathrm{~kW}$ of flexible capacity throughout its operating times to participate in grid response events. As just one of a number of similar units located on this site it would be possible to build up larger capacities by combining multiple units into a response portfolio based on this AHU's performance. The external air temperature data from the case study site's BMS, available at 15-min intervals, were collected for the days on which the previous grid frequency events had occurred, with the corresponding daily min, mean and max temperatures, as displayed in Table 3. The daily external air temperature profiles 
for each of these days are also illustrated in Figure 2, highlighting a considerable range of temperatures across the years analysed. The temperatures recorded on 3 March 2019 present an example of a particularly cold day, when the AHU would likely be operating in its heating mode to maintain a comfortable internal air temperature within the zone. The 19 July 2020 daily profile offers a contrasting example with a much higher average external air temperature recorded and especially high values in the later hours of this summer day. Each of these examples offer interesting potential risks to the indoor thermal environments served by this AHU if it were participating in DR to warrant further detailed investigation.

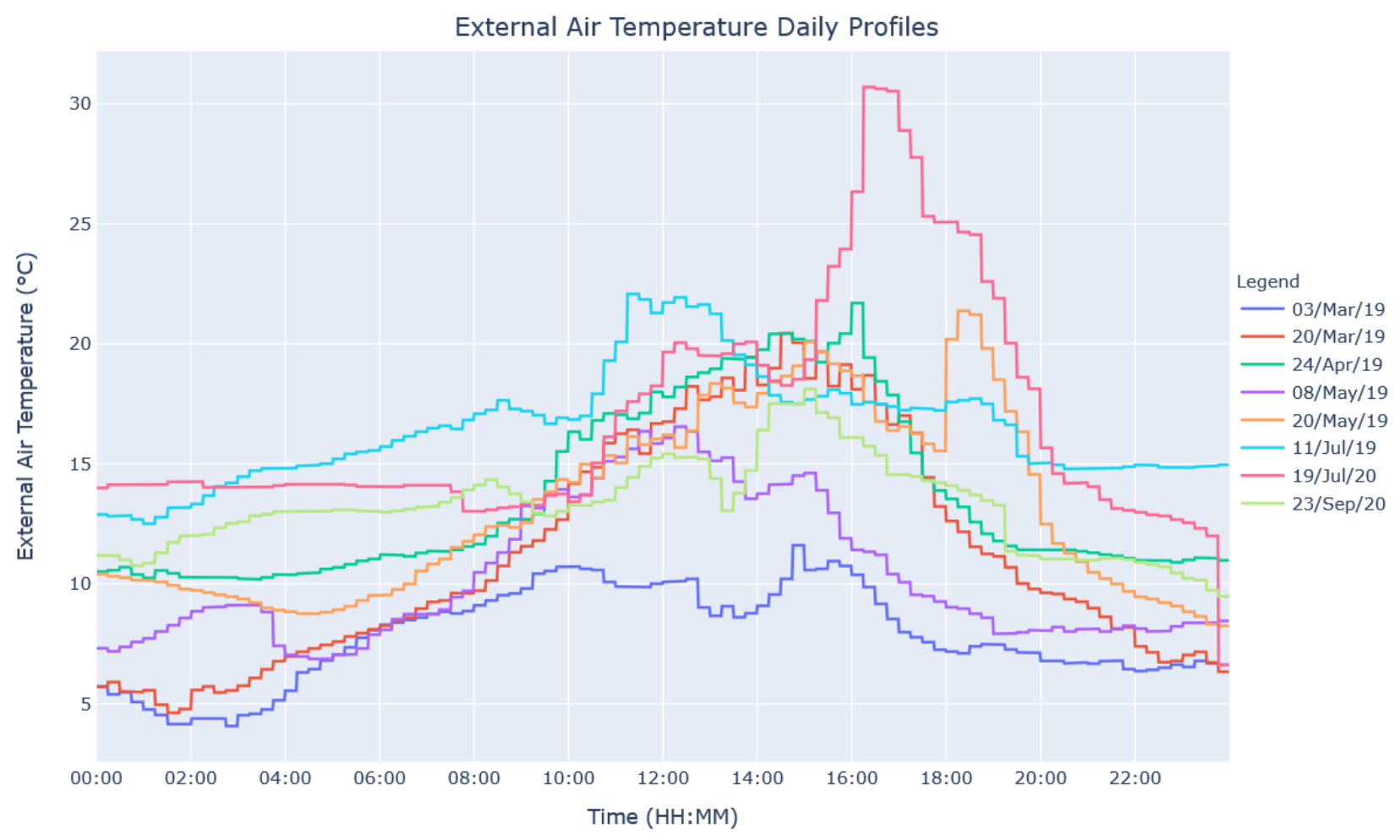

Figure 2. Overview of external air temperature daily profiles from the site's BMS, for each day on which a grid frequency event occurred.

To ensure an adequate evaluation of any risk to the internal thermal environment of the case study site offering its AHU for DR, each of the previous grid event days will be assessed to demonstrate the risk, if any, of their participation. The specifics of each grid frequency event day and evaluation criteria are outlined in Table 4. In addition to the thermal comfort threshold of $20^{\circ} \mathrm{C}$ to $23^{\circ} \mathrm{C}$, the American Society of Heating, Refrigerating and Air Conditioning Engineers (ASHRAE) standards for allowable temperature drifts for human occupancy [56] will also be applied to evaluate the risk. Therefore, under the outlined criteria any deviation outside the $20-23{ }^{\circ} \mathrm{C}$ temperature range, any drift of more than $2.2{ }^{\circ} \mathrm{C}$ in a one hour period or a drift of more than $1.1^{\circ} \mathrm{C}$ in a standalone $15 \mathrm{~min}$ period or during the same one hour period will result in the response being flagged as a risk. In addition to evaluating each of the actual events that occurred, the potential shutoff durations outlined in Table 4 will also be evaluated to assess how long the AHU could safely remain off following a shutoff for DR. This will highlight the potential for this asset to provide longer response durations to the grid and possibly benefit from additional incentive multipliers for short- and longer-duration responses. 
Table 4. Table of scenarios outlining previous actual grid frequency events, including their dates, shutoff times and durations, in addition to the thermal comfort threshold and potential shutoff durations for evaluation.

\begin{tabular}{ccccc}
\hline \multicolumn{2}{c}{ Actual Grid Frequency Events } & \multicolumn{2}{c}{ Evaluation Criteria } \\
\hline Date (dd/mmm/yy) & $\begin{array}{c}\text { Shutoff Time } \\
\text { (hh:mm:ss) }\end{array}$ & Shutoff Duration (s) & $\begin{array}{c}\text { Thermal Comfort } \\
\left.\text { Threshold ( }{ }^{\circ} \mathbf{C}\right)\end{array}$ & $\begin{array}{c}\text { Potential Shutoff } \\
\text { Durations (mins) }\end{array}$ \\
\hline 3/March/2019 & $06: 12: 59$ & 111 & $20-23$ & $5,10,15,20,30,45,60$ \\
20/March/2019 & $16: 46: 16$ & 4 & $20-23$ & $5,10,15,20,30,45,60$ \\
24/April/2019 & $15: 21: 07$ & 5 & $20-23$ & $5,10,15,20,30,45,60$ \\
8/May/2019 & $09: 14: 23$ & 7 & $20-23$ & $5,10,15,20,30,45,60$ \\
20/May/2019 & $14: 54: 12$ & 226 & $20-23$ & $5,10,15,20,30,45,60$ \\
11/July/2019 & $07: 53: 37$ & 5 & $20-23$ & $5,10,15,20,30,45,60$ \\
19/July/2020 & $06: 26: 35$ & 45 & $20-23$ & $5,10,15,20,30,45,60$ \\
23/September/2020 & $11: 02: 15$ & 5 & $20-23$ & $5,10,15,20,30,45,60$ \\
\hline
\end{tabular}

\section{Results}

3.1. Implementation of Methodology

3.1.1. Define Scope (Step 1)

To further this study and advance the industrial sector's engagement with and participation in DR, the comprehensive methodology was applied to the relevant case study site and its encompassed assets. The scope of this project was formalised through a number of interactions with the relevant stakeholders, comprising semi-structured and silent brainstorming and discussion sessions. Using the captured information and the decided outputs, categorised using the affinity diagram technique, the decision was made to consider all energy-using assets onsite for potential participation under each of the relevant and applicable DS3 system service categories. Engagement from each of these stakeholders, with representation from the management level and team member roles in each of the facilities, maintenance, operations and production departments ensured that comprehensive insights were achieved throughout. The communication links with each of these stakeholders were maintained throughout the process to capture any additional feedback or comments and to ensure the long-term sustainability of the project.

\subsubsection{Asset Identification (Step 2)}

Through collaboration with the onsite facilities team and maintenance technicians, each of the asset lists were identified, collected and compiled to form the comprehensive site asset register. Information and data were collected from the onsite metering system and data historians where available. Physical site walks were conducted to confirm the documented information and capture any information not included in these files or through the onsite metering system. Inspecting the assets in person helped to confirm their metering status, nameplate capacities, asset location and other identification tags, as well as electrical connection specifics. Tracing each asset directly back to its assigned bus bar or distribution board helped to confirm these details and ensure that the future decisions were based on accurate information, as this detail in particular is essential to deciding an assets suitability. The completed asset register was securely saved and backed up, in addition to being shared with the relevant stakeholders to confirm its accuracy and ensure that a representative data repository had been created.

\subsubsection{Asset Categorisation (Step 3)}

Once this comprehensive asset register was compiled, the categorisation process was conducted. This consisted of assessing each asset under the methodology's defined suitability criteria. The main element of this considered the rated power of each asset, with the actual response capacity it would be capable of providing, as this has a large influence on its suitability and the value of its inclusion. Additionally, the specific bus bar or distribution board each asset was connected to was important, as this directly influenced 
the ease and complexity of its inclusion. Clusters of suitable assets on a single board were considered particularly desirable, as this minimised the cost and difficulty of the setup for inclusion in a DR aggregation. Furthermore, assets with intrinsic system inertia, known lead times, incorporated redundancy or demonstrated ride-through capacities identified by onsite subject-matter experts were recorded and ranked appropriately. Following the systematic categorisation process, a number of suitable assets were identified onsite, ranked as categorisation level 1 , and the remaining assets were classified into their appropriate categorisation levels, as illustrated in Table 5. This categorised asset register was then securely saved onsite and will be updated to reflect any relevant changes or updates to the assets that may affect their ranking. In cases where an asset is updated and moved to categorisation level 1 it will be considered for participation and included in the site's DR portfolio at the earliest opportunity.

Table 5. Description of asset categorisation levels with examples from the assessment completed at the case study site.

\begin{tabular}{|c|c|c|}
\hline Categorisation Level & Description & Asset Example \\
\hline 1 & $\begin{array}{l}\text { Large reliable capacity, negligible to no impact on the } \\
\text { end use and suitable access to warrant inclusion }\end{array}$ & Selected AHUs, CHP Unit \\
\hline 2 & $\begin{array}{c}\text { Meets all criteria but capacity not large enough to } \\
\text { warrant inclusion at this time }\end{array}$ & Extraction Fans, Pumps \\
\hline 3 & $\begin{array}{l}\text { May be included once minor change to process/SOP, } \\
\text { cost or location/complexity occurs }\end{array}$ & Remaining AHUs, Compressors, Chillers \\
\hline 4 & $\begin{array}{l}\text { Not included unless major change to process/SOP, } \\
\text { cost or location/complexity occurs }\end{array}$ & Production Equipment, Humidifiers, Lighting \\
\hline 5 & $\begin{array}{l}\text { Do not meet any of the criteria and would not } \\
\text { be suitable }\end{array}$ & Emergency Equipment \\
\hline
\end{tabular}

\subsubsection{Risk Assessment and Analysis (Step 4)}

Once each of the assets had been comprehensively evaluated and categorised, the level 1 assets progressed to the next step for further analysis. The first technique in the risk assessment process was an RPN assessment, in which each of the selected assets were evaluated under the four relevant headings: Safety, Environment, Operational and Detectability. Each asset was assigned a relevant number rating, denoting how detrimental the impact of a failure would be under each of the headings, as demonstrated in Table 6. Each of the AHUs in this case received RPNs of 2 as the environment was the only possible risk identified. This was based on the potential risk to the thermal environment within the zones served by these assets and the potential increase in carbon dioxide $\left(\mathrm{CO}_{2}\right)$ levels due to the reduced fresh supplied air, although it was only assigned a minimal risk number of 2 . The remaining categories were also not deemed to pose a risk in any way as an AHU failure would not be deemed a safety risk. These AHUs do not serve or affect production or operation areas and any failure would be visible through the onsite BMS system and therefore would be monitored and easily detectable. The CHP unit in this case received a marginally higher RPN of 4, as the safety element of a failure of this unit in a live site plant room and the repair requirements pose a marginal safety risk. The environmental risk was attributed to higher $\mathrm{CO}_{2}$ production, which would result from separate thermal and electrical units operating to meet the same demand. The operational risk was minimal as there are two other boilers on-site, capable of meeting the demand if required and the CHP is monitored by the site BMS, similarly to the AHUs, and so a failure would be easily detectable.

The next risk assessment technique applied was an SvP matrix, which is particularly useful for highlighting significant risk due to its increasing scale, while also offering a quantitative measure of a number of varying risk factors. The risk of an AHU failing was analysed first, with this particular occurrence receiving an SvP value of 2, as illustrated in Figure 3a. This was largely due to the non-negligible severity of a failure, potentially affecting the internal temperature within the zone served by the AHU. More analysis and 
risk assessment are required to counteract the perceived risk in this area. The second factor of this analysis is the probability of occurrence, which in this case is minimal, as the AHU is switched off daily, routinely monitored through the BMS and is subject to regular maintenance schedules. The SvP of a CHP unit failure was also analysed, as shown in Figure $3 b$, receiving a marginally higher SvP value of 4 . This value was obtained due to the demonstrated ability of the two other gas boilers on site to meet demand if required, therefore reducing operational risk, but the lowered efficiency influenced the severity. By having to rely on separate generation sources, gas for the boilers and electricity from only the grid, the increased overall $\mathrm{CO}_{2}$ production and financial cost of maintaining supply without the CHP unit marginally increases. The probability of a CHP unit failing was deemed to be reasonably low, based on its existing demonstrated performance capabilities. This value was somewhat impacted by the more complex and less frequent maintenance schedule, influenced by external factors, and specialised requirements that could not rule out minor reliability concerns.

Table 6. Risk priority number assessment of selected assets categorised as level 1.

\begin{tabular}{cccccc}
\hline Asset & Safety & Environment & Operational & Detectability & RPN \\
\hline AHU 1 & 1 & 2 & 1 & 1 & 2 \\
AHU 2 & 1 & 2 & 1 & 1 & 2 \\
AHU 3 & 1 & 2 & 1 & 1 & 2 \\
AHU 4 & 1 & 2 & 1 & 1 & 2 \\
AHU 5 & 1 & 2 & 1 & 1 & 2 \\
CHP & 2 & 2 & 1 & 1 & 4 \\
\hline
\end{tabular}

\begin{tabular}{|c|c|c|c|c|c|c|}
\hline \multirow{6}{*}{$\begin{array}{l}\frac{3}{1} \\
\frac{2}{\pi} \\
\frac{0}{0} \\
\frac{0}{2}\end{array}$} & 6 & 12 & 18 & 24 & 30 & 36 \\
\hline & 5 & 10 & 15 & 20 & 25 & 30 \\
\hline & 4 & 8 & 12 & 16 & 20 & 24 \\
\hline & 3 & 6 & 9 & 12 & 15 & 18 \\
\hline & 2 & 4 & 6 & 8 & 10 & 12 \\
\hline & 1 & 2 & 3 & 4 & 5 & 6 \\
\hline (a) & \multicolumn{6}{|c|}{ erity } \\
\hline
\end{tabular}

\begin{tabular}{|c|c|c|c|c|c|c|}
\hline \multirow{6}{*}{$\begin{array}{l}\frac{2}{5} \\
\frac{0}{\pi} \\
\frac{0}{0} \\
\frac{0}{2}\end{array}$} & 6 & 12 & 18 & 24 & 30 & 36 \\
\hline & 5 & 10 & 15 & 20 & 25 & 30 \\
\hline & 4 & 8 & 12 & 16 & 20 & 24 \\
\hline & 3 & 6 & 9 & 12 & 15 & 18 \\
\hline & 2 & 4 & 6 & 8 & 10 & 12 \\
\hline & 1 & 2 & 3 & 4 & 5 & 6 \\
\hline (b) & \multicolumn{6}{|c|}{ Severity } \\
\hline
\end{tabular}

Figure 3. Severity vs. probability matrix demonstrating (a) a level 2 performance for an AHU Failure and (b) a level 4 performance for a CHP unit failure.

The final risk assessment technique implemented on the case study site was the BT analysis, which provided a clear diagrammatic illustration of the lifecycle of a possible failure from sources of risk, including prevention controls and mitigation measures all the way through to potential consequences. In both evaluations of an AHU and CHP unit failure, it was found that the existing prevention controls and mitigation strategies were generally adequate to minimise the identified sources of risk, as shown in Figure 4. The main consequence of an AHU failure identified was a deviation beyond the allowable internal temperature limits, which can be evaluated further through modelling and analysis to eliminate any perceived unacceptable risk. The next most prominent consequence arising in both evaluations is the potential requirements for additional parts or servicing, which can easily be further mitigated by reviewing maintenance schedules and the stock of replacement parts. Finally, in the case of the CHP, the increased demand on existing boilers or the grid electricity supply is potentially a noteworthy consequence. The impact of this is generally minimal when viewed in relation to its occurrence compared to the carbon offset and financial benefit achieved through the actual participation in the DR scheme. 


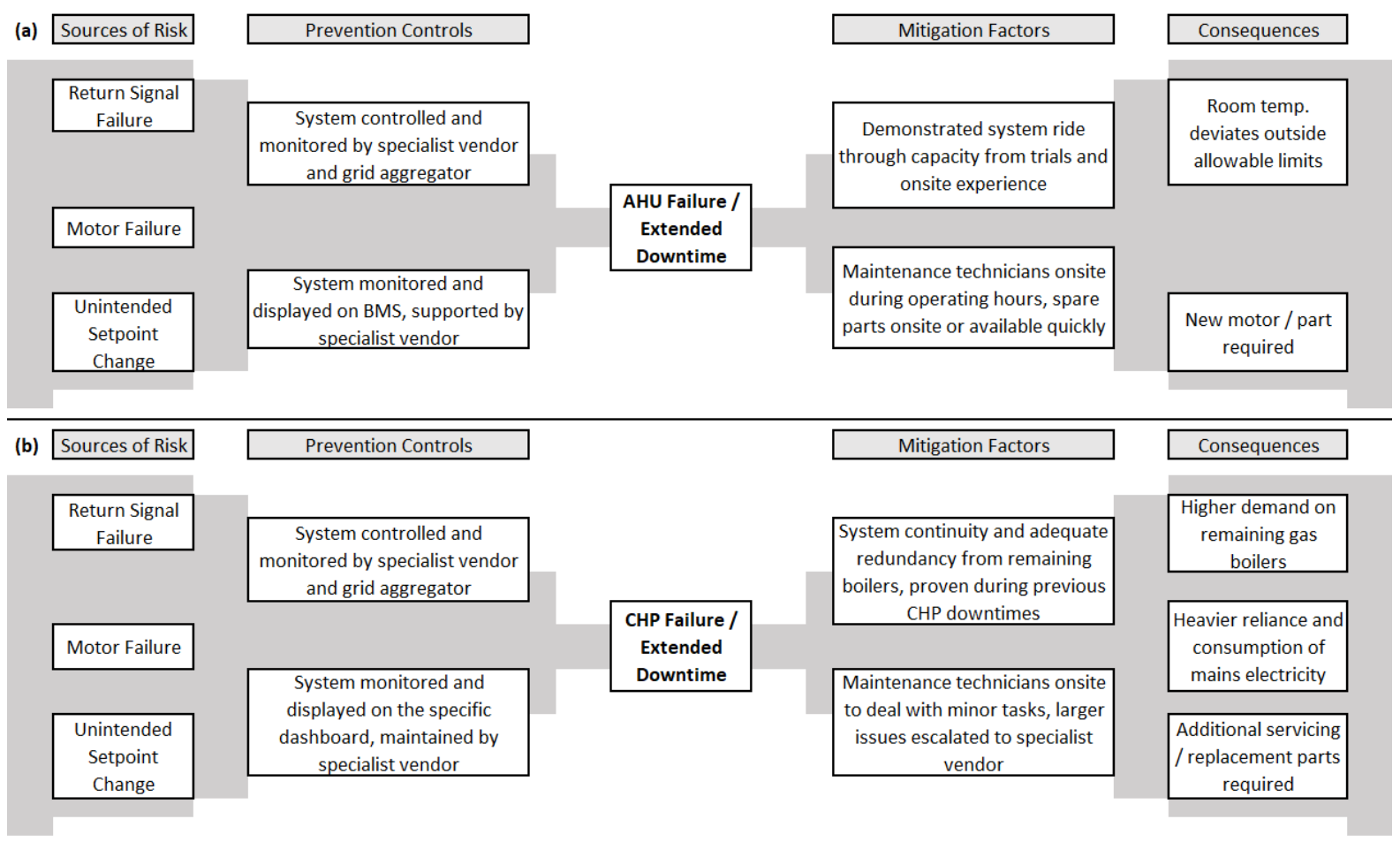

Figure 4. Bow tie analysis of (a) an AHU failure or extended downtime and (b) a CHP unit failure or extended downtime, illustrating the sources of risk, prevention controls, mitigation factors and potential consequences.

\subsubsection{Modelling AHU Participation (Step 5)}

To ensure a comprehensive assessment of any risk to the indoor thermal environment on the case study site if the AHU was shutoff for DR, each of the previously occurring grid frequency events during 2019 and 2020 were evaluated using this modelling tool [52]. Considering each of the actual grid event times, which would have triggered a response based on the system frequency, the AHU was shut off to observe the effect on the indoor air temperature within the zone, as shown in Figure 5. None of the previous grid events would have caused the indoor air temperature to drift outside of the temperature limits for the 5-min shutoff duration. As the longest previous grid event was less than $5 \mathrm{~min}$, lasting for only $3 \mathrm{~min}$ and $46 \mathrm{~s}$, it is clear that no risk or unacceptable impact on the indoor air temperature would have occurred, therefore demonstrating that there would be no risk to the site if it were participating in a DR scheme during these events. To analyse the potential further, the $\mathrm{AHU}$ was set to remain off for longer durations for the same trigger points to assess how long it could safely remain off when responding to these grid events. The event that occurred on 3 March 2019 would not have encountered any risk across each of the shutoff durations, whereas the 8 May 2019 and 23 September 2020 events would have been considered a risk only if they were to remain off for an hour. As illustrated in Figure 5, the remaining grid event days each exceeded the upper temperature limit and would be considered a risk across the 30-, 45- and 60-min durations.

The comprehensive risk analysis results for each of the grid event days and shutoff durations are presented in Figure 6. This demonstrates the performance capabilities and any potential risk to the indoor air temperature based on the thermal comfort threshold limits outlined in Table 4 and illustrated in Figure 5 and the ASHRAE drift criteria of $2.2{ }^{\circ} \mathrm{C}$ across a one-hour period and $1.1^{\circ} \mathrm{C}$ within this one-hour period or at any stage. None of the grid event days incurred any risk under these criteria for shutoff durations less than $20 \mathrm{~min}$, further demonstrating the considerable potential for DR with these assets. The 24 April 2019 and 20 May 2019 events were the only grid event days to encounter any risk in the 30-min category, both due to internal air temperatures exceeding the $23^{\circ} \mathrm{C}$ 
limit. None of the grid event days analysed were deemed a risk according to the ASHRAE temperature drift criteria.

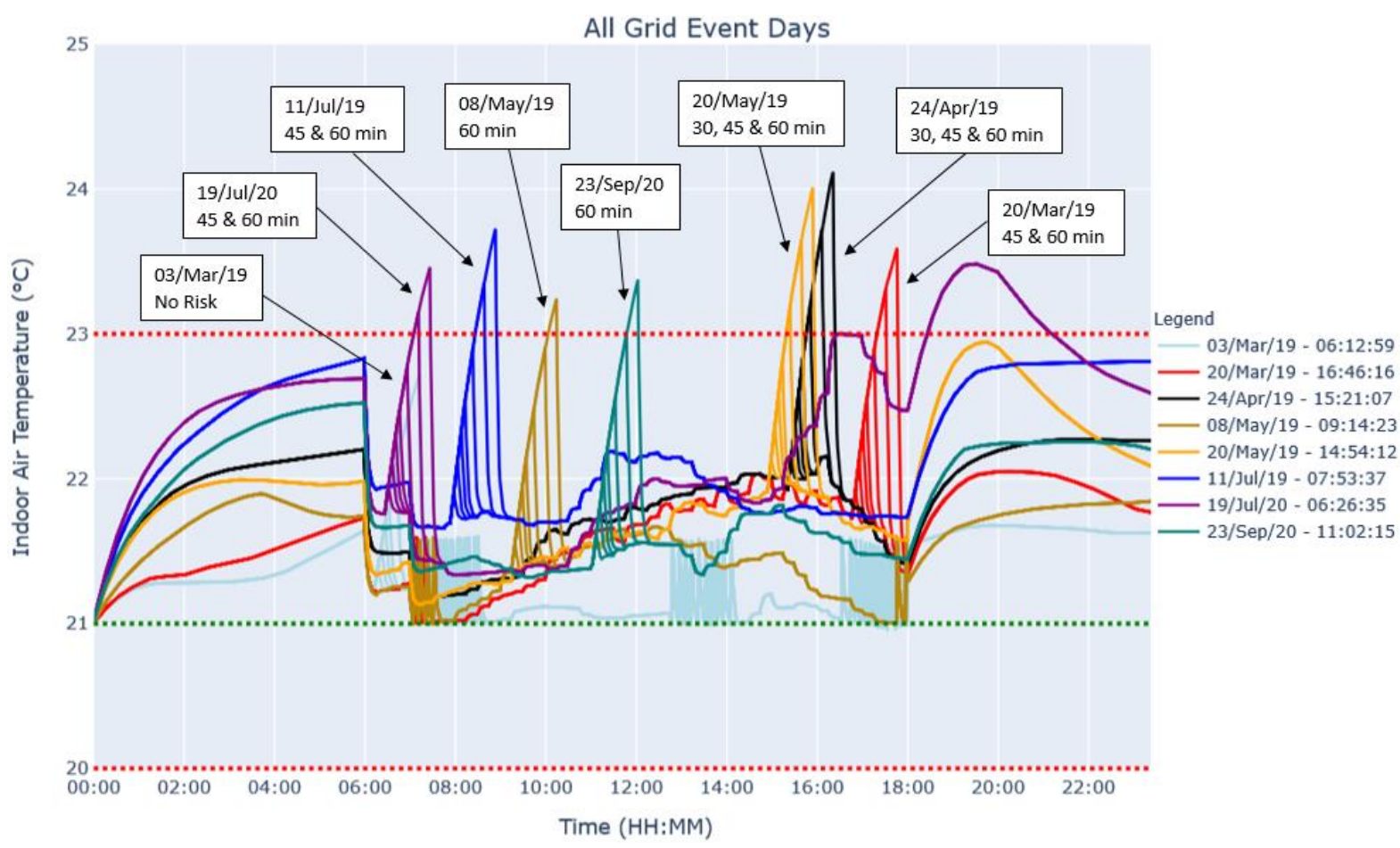

Figure 5. Overview of indoor air temperature within the zone for each grid frequency event day, demonstrating AHU performance over each of the shutoff durations, with red dashed lines depicting temperature limits.

\begin{tabular}{|c|c|c|c|c|c|c|c|}
\hline & \multicolumn{7}{|c|}{ Shutoff Duration (min) } \\
\hline & 5 & 10 & 15 & 20 & 30 & 45 & 60 \\
\hline $\begin{array}{c}\text { 03/Mar/19 } \\
\text { 06:12:59 }\end{array}$ & & & & & & & \\
\hline $\begin{array}{c}20 / M a r / 19 \\
16: 46: 16\end{array}$ & & & & & & & \\
\hline $\begin{array}{c}\text { 24/Apr/19 } \\
\text { 15:21:07 }\end{array}$ & & & & & & & \\
\hline $\begin{array}{c}\text { 08/May/19 } \\
\text { 09:14:23 }\end{array}$ & & & & & & & \\
\hline $\begin{array}{c}\text { 20/May/19 } \\
\text { 14:54:12 }\end{array}$ & & & & & & & \\
\hline $\begin{array}{c}\text { 11/Jul/19 } \\
\text { 07:53:37 }\end{array}$ & & & & & & & \\
\hline $\begin{array}{c}19 / J u l / 20 \\
06: 26: 35\end{array}$ & & & & & & & \\
\hline $\begin{array}{c}23 / \text { Sep/20 } \\
\text { 11:02:15 }\end{array}$ & & & & & & & \\
\hline
\end{tabular}

Figure 6. Overview of risk levels for each grid frequency event day and shutoff duration, with no risk represented in green and any excursion outside of allowable limits or comfort criteria causing a risk coloured in red. 
Each of the AHU shutoffs for a grid event caused the indoor air temperature to drift by some amount, as shown in Figure 7; however, none of the modelled events exceeded the $2.2{ }^{\circ} \mathrm{C}$ limit mandated by the ASHRAE standard. The event occurring on 3 March 2019 presented the lowest temperature drift of the days analysed, with a mean drift of only $0.71{ }^{\circ} \mathrm{C}$ and with the largest drift value only reaching $1.46^{\circ} \mathrm{C}$. This is likely due to the event occurring early in the day and therefore being less influenced by occupancy and activity levels in the internal zone. The low risk to indoor thermal environments for AHUs participating in DR can be shown by the mean temperature drift across all events up to an hour in duration falling between $0.71{ }^{\circ} \mathrm{C}$ and $1.04{ }^{\circ} \mathrm{C}$, which is well within the limits allowed by the ASHRAE standards. Furthermore, the median temperature drift of each of these events fell between $0.59{ }^{\circ} \mathrm{C}$ and $0.87^{\circ} \mathrm{C}$, as shown in Figure 7 , which is also clearly within the allowable limits. The grid events incurring the largest drift range and variability were the 24 April 2019 and 20 May 2019 events. Both of these events occurred later in the day compared to some of the other events that took place during the summer months, when higher risks of overheating may be expected. This can generally demonstrate that there is a lower risk when responding to grid events earlier in the day, or during the first $6 \mathrm{~h}$ of the AHU schedule on the case study site rather than the second, from 12:00 to 18:00.

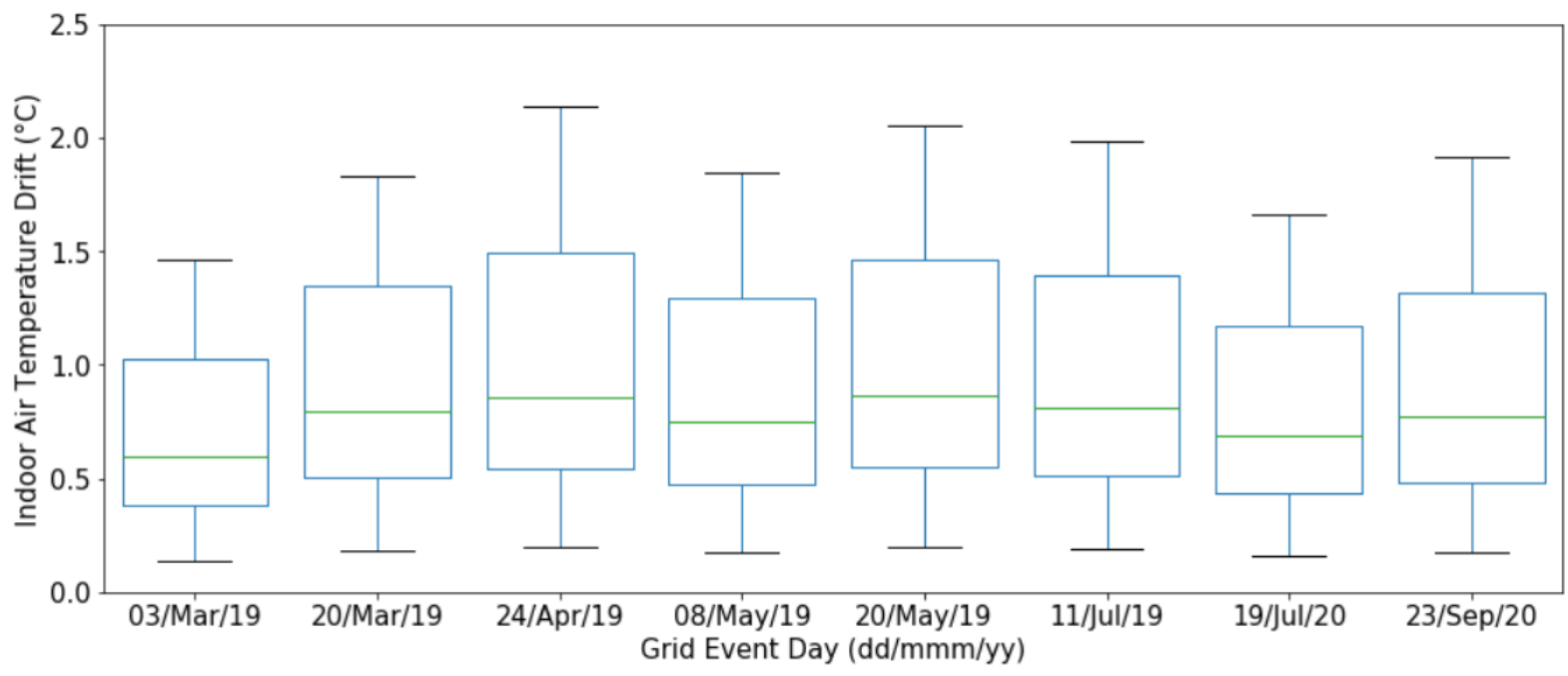

Figure 7. Box-and-whisker plot of indoor air temperature drift for all durations on each grid frequency event day, with median represented by an internal green horizontal line.

\subsubsection{Final Implementation (Step 6)}

Based on the asset selection, categorisation and risk assessment process completed on the case study site it was found that the six assets classified as level 1 would be suitable for DR and electricity market participation. Of these assets, the five AHUs and one CHP unit located in the same building could form a useful flexible capacity, either individually or as an aggregated response portfolio. In this case, scaling the combined capacity of the suitable AHUs from the $15 \mathrm{~kW}$ case study unit selected for further analysis, there is potential for up to $75 \mathrm{~kW}$ of flexible capacity from just the AHUs in this building. Accounting for exceptional circumstances or the potentially reduced participation of certain AHUs, it is realistic to expect that between 35 to $75 \mathrm{~kW}$ of flexible capacity should be consistently available from this site to contribute to DR schemes. Based on the evaluation of the representative case study building, this range of available flexible capacity provides an insight into the potential throughout the wider industrial sector and offers a general depiction of what can realistically be expected from comparable sites and similar buildings in this area. 


\subsection{Impact and Scaling Potential \\ 3.2.1. Scaling Scenarios}

Once the methodology has been completed on one site, the true value can be highlighted by scaling this single-site use case up to similar representative industrial groups, such as local areas or larger-scale national initiatives. An interesting small-scale representation of Irish manufacturing companies is presented by the Cork Lower Harbour Group (CLHG) of multinational companies of a similar scale and sector. The CLHG is made up of the two DePuy Synthes buildings, Thermo Fischer, Janssen Biologics and Novartis, as demonstrated in Table 7, with each building located reasonably close to Ringaskiddy in the Cork lower harbour area. Each of these buildings would have AHUs similar to the case study site and it would therefore be reasonable to assume that a comparable capacity would be achievable on each site within this compilation. Further to this small aggregation of four companies, the next step up for scaling potential captures several equally representative large companies within the industrial sector across the Cork Area. This collection includes the companies from the Ringaskiddy area, with a few additions, as well as further representatives from Carrigtwohill, Little Island and Model Farm Road, each of which are home to some of the largest companies within the industrial sector close to Cork city. The remaining two categories for scaling potential in Table 7 are selections based on the Irish LIEN group [17]. The first of these accounts for only the Pharma/Chem and Healthcare companies, of which there are 43 and 26, respectively, as they are more closely related to the case study site. The final grouping contains all of the 199 companies currently part of the LIEN, of which the proclaimed message is to work together to improve their energy performance and inspire others to follow, making them a group that is well suited to adopt this concept. Based on the single-case study site and each of these potential groupings, it is possible to provide a detailed analysis of the potential achievable on a national scale. These capacity figures will help to develop our understanding of the potential impact and benefits of advancing the industrial sector's participation in DR schemes using this methodology.

Table 7. Overview of four potential groupings this concept could be implemented in and scaled to within the Irish industrial sector.

\begin{tabular}{|c|c|c|c|c|}
\hline Grouping & CLHG & Cork Area & LIEN 1 & LIEN 2 \\
\hline $\begin{array}{c}\text { Potential } \\
\text { Companies }\end{array}$ & $\begin{array}{c}\text { DePuy Synthes, } \\
\text { Thermo Fischer, } \\
\text { Janssen Biologics, } \\
\text { Novartis }\end{array}$ & $\begin{array}{c}\text { Ringaskiddy (DePuy Synthes, Hovione, Thermo } \\
\text { Fischer, Novartis, Janssen Biologics, Pfizer) } \\
\text { Carrigtwohill (Gilead Sciences, Stryker, AbbVie, } \\
\text { GE Healthcare, Merck) } \\
\text { Little Island (PepsiCo, Janssen Pharma, Pfizer) } \\
\text { Model Farm Road (Boston Scientific, Stryker) }\end{array}$ & $\begin{array}{l}\text { Pharma/Chem (43) } \\
\text { and Healthcare (26) }\end{array}$ & All Companies \\
\hline Companies & 4 & 16 & 69 & 199 \\
\hline
\end{tabular}

\subsubsection{Scaling Results}

The case study site implementation and evaluation found and demonstrated that there was realistic, risk-free potential of approximately 35 to $75 \mathrm{~kW}$ available from a single industrial site. Based on these figures, it was possible to scale up the impact of this concept into the representative low and high potential capacity figures presented in Table 8. The first two groupings of the CLHG and the companies within the Cork area offer a reasonably conservative capacity to the national grid, with neither grouping exceeding $2 \mathrm{MW}$. The high potential Cork area capacity of 1.2 MW does present a useful local response capacity, however, particularly in the case of regional grid issues or challenges caused by the electrical hub of Cork city. If this concept was adopted by either of the LIEN grouping scenarios, a considerable impact and numerous benefits could be provided to the national electricity grid. If this were implemented across the entire LIEN, the high potential figure would provide close to $15 \mathrm{MW}$ of flexible capacity to the grid, which could be a vital addition to the current control and reliability measures available to the TSOs. 
Table 8. Demonstration of the low and high potential capacities achievable by a single site and the four possible groupings within the Irish industrial sector to which this concept could be scaled up.

\begin{tabular}{cccccc}
\hline Grouping & $\begin{array}{c}\text { Single Site } \\
(\mathbf{k W})\end{array}$ & $\begin{array}{c}\text { CLHG } \\
\mathbf{( k W )}\end{array}$ & $\begin{array}{c}\text { Cork Area } \\
\mathbf{( k W )}\end{array}$ & $\begin{array}{c}\text { LIEN 1 } \\
\mathbf{( k W )}\end{array}$ & $\begin{array}{c}\text { LIEN 2 } \\
(\mathbf{k W})\end{array}$ \\
\hline Low Potential & 35 & 140 & 560 & 2415 & 6965 \\
High Potential & 75 & 300 & 1200 & 5175 & 14,925 \\
\hline
\end{tabular}

Each of the scenarios offer value of varying scales, both financially to their site and in terms of providing flexible capacity to the national electricity grid. The impact of each low and high potential scenario is illustrated in Figure 8, compared to a variety of actual existing capacities participating in the Irish national grid for context. Two windfarms within the Electricity Supply Board (ESB) generation portfolio that offer comparable generation capacity figures were selected. Carnsore windfarm has fourteen turbines, offering 11.9 MW, and Grouselodge windfarm has six larger turbines, offering $15 \mathrm{MW}$ of capacity to the grid [57]. The Indaver waste-to-energy (WTE) steam turbine offers $17 \mathrm{MW}$ of generation capacity [12], 15.1 MW of which is exported to the national grid [58]. The Existing Industrial Capacity of $9 \mathrm{MW}$, made up of small-scale generators used for supply during peak demand or similar circumstances, is also of comparable size [12]. Finally, the Statkraft $11 \mathrm{MW}$, 5.6 MWh lithium-ion battery energy storage system (BESS) in Kilathmoy, Co. Kerry [59], already contracted for DS3 system services, provides an interesting comparison to the scaling scenarios as they could potentially fall in the same response categories. Both the low and high potential capacities offer a useful fraction of each of these capacities to the grid and therefore could offer valuable flexibility in the event that any of these examples encountered issues with reducing their output. The high potential LIEN 2 scenario could replace in full the Existing Industrial Capacity, the Statkraft BESS or Carnsore windfarm if they were to go offline suddenly with capacity to spare. It could also replace a significant segment of the output from the Indaver WTE plant or Grouselodge windfarm in the event of an unexpected issue or sudden loss of wind resources. This would allow the grid to recover and quickly replace this capacity seamlessly, eliminating the risk of frequency events and even blackouts, which may not be achievable in the future with the current levels of connected flexible capacity. Furthermore, this capacity grouping could form part of a larger existing or planned virtual power plant, or with some additional coordination work could even become a virtual power plant in its own right.

In addition to the valuable benefits to the national grid, there are also financial gains to be made by a site through incentive payments for participating in the DS3 system services [60]. As there are no stated minimum capacity thresholds for participation in these system services - only participation capability stipulations and minimum data requirementsthe major consideration for potential participants is cost-effectiveness. Therefore, an evaluation and demonstration of potential revenue streams and financial gains from the incentive structures would provide value to potential participants and the decision-makers driving their engagement or considering even larger-scale contributions. The annual availability payments for a single site, excluding additional bonus payments, for the low and high potential capacities, of 35 and $75 \mathrm{~kW}$, respectively, outline this potential in Table 9 and are noteworthy, considering the proven low risk of participation. This is emphasised by the case study site not experiencing any risk during the previous grid frequency events through to twenty minutes, as shown in Figure 6, which covers the duration of each of the five DS3 system services presented in Table 9. There are notable financial gains to be achieved in the primary operating reserve category, with a single site having the potential to receive a base annual participation payment of EUR 993 for only $35 \mathrm{~kW}$ and up to EUR 2129 for a higher potential capacity of $75 \mathrm{~kW}$. 


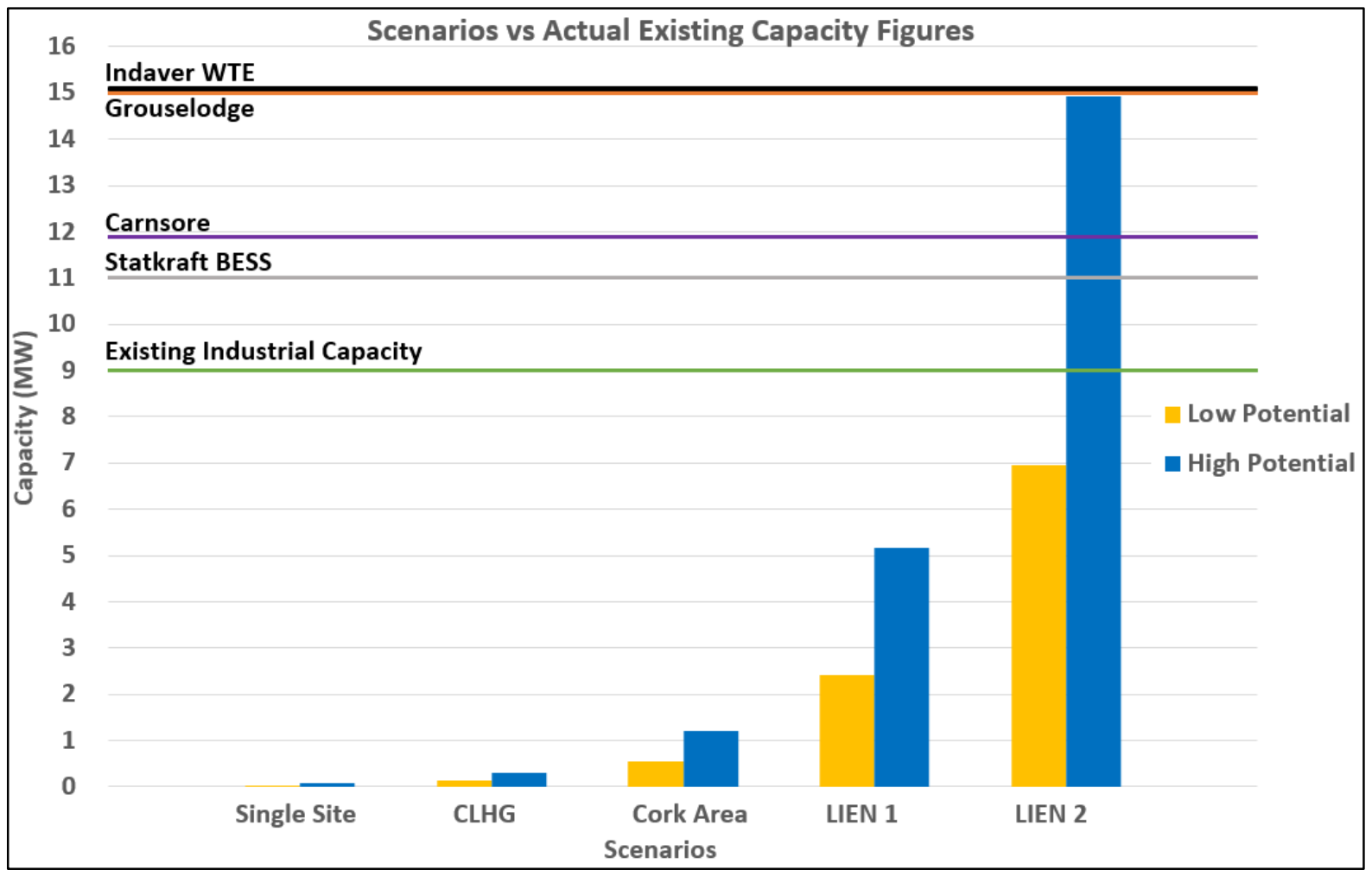

Figure 8. Bar chart illustrating the low (Yellow) and high (Blue) potentials achievable by each grouping scenario compared to actual existing capacity figures, illustrated by the horizontal annotated lines.

Table 9. Overview of annual payments achievable by a single site offering low potential and high potential capacities under five of the frequency response DS3 system services.

\begin{tabular}{cccc}
\hline DS3 System Service Category & Delivery Time (s) & Low Potential-35 kW (EUR) & High Potential-75 kW (EUR) \\
\hline Fast Frequency Response (FFR) & $2-10$ & 662 & 1419 \\
Primary Operating Reserve (POR) & $5-15$ & 993 & 2129 \\
Secondary Operating Reserve (SOR) & $15-90$ & 601 & 1288 \\
Tertiary Operating Reserve 1 (TOR1) & $90-300$ & 475 & 1018 \\
Tertiary Operating Reserve 2 (TOR2) & $300-1200$ & 380 & 815 \\
\hline
\end{tabular}

\section{Discussion}

There are a number of assets on an industrial site with the potential to provide flexible capacity for DR schemes, as illustrated in Table 5. Depending on the site, the number of level 1 assets can vary, as can the potential to move assets through the levels, particularly from level 2 and 3 to level 1, which has a significant impact on the capacity figures achievable on a single site. On less risk-averse sites, industries with considerably more ancillary services or sites with more capital available to tailor their processes or site layout to target these services, additional assets can be included within the level 1 category. There is potential for certain compressors or chillers to be included in response portfolios, if the buffer tanks are capable of safely maintaining an uninterrupted supply throughout the duration that the compressor or chiller is turned off for response. For more sophisticated systems with integrated stepped controls or variable speed drives there is the potential to reduce the compressor or chiller electrical demand by the defined capacity amount for the duration of the response. This ensures that the system or buffer tank is still being partially supplied, eliminating instances where it would not be feasible to shut the asset down entirely for DR for any amount of time. Additional assets from the level 2 category, such as certain non-essential pumps or fans, could be moved to level 1 if their electrical feed was closer to other participating assets. A number of smaller assets may not be feasible 
for inclusion because wiring them into the response portfolio or the additional hardware required may not be cost-effective based on their individual capacities.

One of the main considerations and factors in deciding an asset's suitability is the location of its electrical feed. Assets that are supplied by the same electrical panel or bus bar are the most suitable, as this minimises the need for additional hardware and communications equipment. For frequency-controlled DR, generally a single mains supply frequency-monitoring device is placed on the participating site within the specified electrical panel to send the shutoff signal to the assets when required by the grid. Due to the tight time constraints and the importance of quick, validated responses, these devices must be located as close to the main responding assets as possible. Therefore, in the case of a number of assets responding as an aggregated capacity, the ideal or most suitable case would be one in which the assets are all supplied from the same electrical panel. This does not mean that sites with dispersed assets should be discounted, as there are methods to incorporate assets in this situation, albeit with additional complexities and capital costs. The simplest of these is to install additional monitoring and signalling hardware on each applicable electrical panel, but there is an additional cost and this will influence the overall feasibility and cost-effectiveness of the site's participation. Another option is to install communication devices to relay the signal from the main device to each of the other responding assets. This is a more cost-effective method but it can incur issues based on the distances between responding assets' electrical panels, communication protocols within the industrial environment and validation of response performance requirements. These solutions do increase the ability of certain sites to increase their response capacities, particularly if AHUs are their only level 1 assets and the office spaces are dispersed across vast industrial complexes. These options can encourage the potential participation of non-office-space AHUs that may or may not be co-located on electrical panels to increase the capacities achievable with further changes to operating procedures or the placement of additional monitoring equipment.

In light of the modelling conducted as part of the comprehensive evaluation of an industrial AHU's DR potential, a number of practical outcomes were uncovered. The fact that no risk was encountered during the 5-min shutoffs for any of the previous grid frequency events is very promising for this type of asset's participation. This clear demonstration, highlighting that there is no impact on the indoor thermal environment, builds confidence in its performance and contributes to reducing the perceived risk of its inclusion in DR schemes. The illustrated ability for this asset to respond and remain off for at least twenty minutes, as shown for each of the previous grid events, further compounds its strong potential. This significant risk-free window for response allows the participants and TSOs the additional flexibility to provide the optimal response across the variety of response categories, based on the specific system needs required at the time. This flexibility and considerable potential can be increased on sites with marginally less stringent temperature limits. If the upper thermal comfort threshold limit was increased from $23^{\circ} \mathrm{C}$ to $24^{\circ} \mathrm{C}$, only a 60-min shutoff during two previous grid events-20 May 2019 and 24 April 2019-would have been classified as a risk. This incremental temperature increase may not be acceptable on certain sites, but the potential performance gains would be very significant where suitable, as this would allow greater flexibility and a risk-free response horizon of at least an hour in the majority of scenarios considered. Another interesting point arising from the modelling evaluation is that there is generally a greater risk of unacceptable conditions later in the day. The participant could choose to opt out of responding to grid frequency events during these times, if this were included in their performance contract, although this may incur financial penalties or, at the very least, missed revenue for potential performance. The risk-versus-reward relationship may prompt further analysis on a site-specific level. However, the minimal increase in risk would considerably affect any site's financial benefit and the risk would be acceptable in most cases. Overall, the completed evaluation further demonstrates the considerable DR potential available from industrial AHUs and highlights that the levels of risk in practice are much lower than may have been perceived. 
The potential capacities achievable through the implementation of this concept offer a number of interesting and increasingly valuable benefits to the national electricity grid. The 35 to $75 \mathrm{~kW}$ capacity expectation may vary based on different site processes and configurations. However, it does provide a strong foundation for a representative range of participation capabilities across a large collection of industrial sites, allowing sites with significantly higher and exceptionally lower suitable capacities to be captured within one grouped figure that represents the impact potential of the LIEN adopting the concept in this case. The potential capacity scenarios illustrated in Figure 8 demonstrate the impact in relation to existing generation sources of a similar scale; however, the additional flexible capacity achievable can also have a greater impact on the national grid in the long term. Currently, the impact of data centres in Ireland is an especially topical issue and the potential capacities of this concept may assist the TSOs to some extent. Data centres are generally considered a stable base load demand on the grid and so TSOs will often incorporate further variable renewable sources of energy onto the grid on the basis that these data centre capacities will remain static. Although the potential capacities of this concept are not directly comparable to the estimated $108 \mathrm{MW}$ Facebook data centre in Clonee, Co. Meath, which is currently the largest in Ireland [61], the potential capacities are comparable to nine of the 57 data centres with MW capacities available in Ireland [61]. This means they would be capable of responding to any fluctuation or disturbance to the grid caused by an issue at one of these data centres, such as the 4 MW CIX-Cork Internet eXchange data centre in Co. Cork, Ireland [61]. The increased ability to control fluctuations within the grid can reduce the pressure on the TSOs to rush the repair of traditional fossil fuel plants. The two combined-cycle gas turbine plants in Whitegate, County Cork and Huntstown, County Dublin were recently fast-tracked for repair at great cost, due to fears of supply shortfalls and even blackouts on the Irish grid. The potential capacity scenarios are not directly comparable to the respective capacities of Whitegate's $444 \mathrm{MW}$ and Huntstown's $750 \mathrm{MW}$, which are made up of two $342 \mathrm{MW}$ and $408 \mathrm{MW}$ turbines [12]. However, this additional ability to maintain control of the grid at higher levels of renewable penetration and with the remaining electricity supply still online, the urgency to repair or upgrade these large fossil fuel plants is reduced. Furthermore, increasing the grid's resilience and controllability allows the TSOs to maintain or increase the rate at which older, less efficient plants are decommissioned and removed from the generation mix. Replacing the need for fossil fuel plants used only for peak demand times or other similar scenarios would help to decrease the reliance on carbon-intensive fuels and minimise national emissions in line with international targets.

The financial incentive structures and payment schemes are designed to encourage sites to participate in the DS3 system services, assisting the safe and reliable management of the national electricity grid. This has a two-fold benefit as a site receives payment for participation but also has the opportunity to reduce its electricity consumption during these events. The grid, according to the definition of these events, is usually under considerable stress, which generally equates to higher unit prices for electricity during these times. A participating site would be able to reduce its demand for electricity during these events and lower its overall electricity costs in some cases. Furthermore, as the incentive structures incorporate an availability payment category, participants will still receive this base payment whether they are called to respond numerous times, only once or even not at all, depending on the grid requirements each year. Limitations can also be placed on the frequency of responses, with some contracts ensuring that a site will not be called to respond twice in the same month. Similar stipulations or performance limitations can be included based on the participant's requirements or specific requests and the contractor or TSO's ability to facilitate these, which further reduces any potential hesitation or possible risk of participation. Additionally, a site has the opportunity to maximise their financial benefit through payment multipliers called scalars. One of these scalars offers 1.5 times the fast-frequency response payment for a site that is capable of providing a fast-frequency response and remaining off, for the continuous provision of a response until the tertiary 
operating reserve 1 category is satisfied [62]. This means responding within two seconds and maintaining this response for $5 \mathrm{~min}$, which would result in an annual payment of EUR 3063 or EUR 6563 for a site offering 35 or $75 \mathrm{~kW}$ of response capacity, respectively. This provides considerable opportunities for industrial AHUs if they can be set up to meet these requirements, as they have proven their ability to remain off for the specified duration, incurring no impact to their served area on the site.

\section{Conclusions and Future Work}

The overarching goal of this study was to advance the industrial sector's engagement and participation in DR programmes and increase the flexible response capacities available to TSOs and the national electricity grids. The foundations of this were achieved through the development and presentation of a methodology to effectively identify and categorise assets for DR on industrial sites. This was advanced through supplementary works to evaluate any perceived risk associated with their participation, allowing a sustainable portfolio of response assets with acceptable risk levels to be created by any industrial site intending to participate in national DR programmes. The implementation of this methodology on a case study site identified five AHUs and a CHP unit immediately classified as level 1 and low-risk assets suitable for DR participation. Based on this evaluation and specifically the AHU units, it was determined that it is realistic to expect between 35 to $75 \mathrm{~kW}$ of flexible capacity from industrial AHUs on a single site, allowing this participant to offer flexible capacity to the TSO and benefit themselves and their national electricity grid.

Additional outputs of this research demonstrate the implementation of an internal air temperature model to investigate any risks associated with industrial AHUs participating in actual DR events. It demonstrated that the case study site could have safely shutoff its AHU capacity for the duration of all previous grid frequency events in 2019 and 2020. Furthermore, these assets could have remained off and risk-free for at least 20 min in each case and for $75 \%$ of all scenarios analysed, demonstrating the significant potential available from these response assets. This study also highlighted that there is generally a lower risk of AHUs participating in DR earlier in the day, compared to the mid-afternoon hours, particularly in the hotter summer months. The overall low risk of these assets participating in DR is further highlighted by the mean temperature drift across all actual events up to an hour in duration, falling between $0.71{ }^{\circ} \mathrm{C}$ and $1.04{ }^{\circ} \mathrm{C}$, which are safely within the $2.2{ }^{\circ} \mathrm{C}$ limit allowed by the ASHRAE standards. The scaling potential and possible impact on a local, regional and national scale of this concept is also presented in this study. Based on the higher potential of a single site, it was illustrated that if this concept were adopted on a national scale in Ireland, approximately $15 \mathrm{MW}$ of capacity could be achievable. This figure is comparable to a number of existing windfarms, BESSs and even a WTE generation plant already operating on the Irish national grid, which illustrates the considerable impact potential if this were implemented in the future. Finally, the capacities expected on a single site from the most conservative and lowest-risk assets, show the potential to receive payments of between EUR 993 and EUR 2129 annually for participating in the primary operating reserve DR category only. Up to EUR 6563 could also be achieved by responding to the fast-frequency trigger and remaining off in response for the top four response categories or a total of $5 \mathrm{~min}$, which was shown to incur no risk to the indoor thermal environment. These financial benefits from the lowest-risk assets offer a demonstration of the potential that is easily achievable and provide the foundation to develop and include additional assets to increase the onsite portfolio, therefore benefitting from even higher capacities and associated payments. Overall, this research helps to expand the body of knowledge and understanding of industrial DR and demonstrates the significant flexible capacities available within this sector. This evaluation further illustrates the low risk and considerable benefits to the industrial participant of increasing their engagement in DR, as well as the greater benefits to the TSOs and the wider national electricity grid.

Further insights and valuable information may also be gained by conducting future work to continue this study. More in-depth analysis and investigation of larger-capacity or 
higher-risk assets, particularly from the level 2 and level 3 categories, would greatly benefit potential participants. Supplementary investigations and evaluation of the performance capabilities of assets such as compressors and chillers would greatly increase the capacities available from the industrial sector and enhance its potential low-risk asset portfolio. To strengthen this study and further build confidence in the presented results, additional grid data could be investigated. By analysing more frequency data and actual grid events before 2019 and from 2021 onwards, the existing results could be reinforced, as well as potentially uncovering other valuable findings. A possible limitation of this study is the potential scaling scenarios, as the groupings and assumption that each participant would engage may not comprehensively reflect the real-world conditions. However, these scenarios are designed to give a general overview and broad-stroke depiction of the scaling potential of this concept. To further hone in on this area and improve the accuracy of these scenarios, a more comprehensive and detailed study of each company or building within the LIEN or the wider industrial sector could be conducted to capture each individual's specifications. Finally, through additional detailed cost and performance analyses, the potential financial gains and incentive payments achievable could be presented even more clearly. This would help to outline the benefits of participation further and possibly outline a defined minimum capacity requirement to ensure cost effectiveness for the participant, which may help to encourage more industrial engagement in DR. The supplementary cost and payment details would benefit decision makers in this area, in addition to highlighting the value of participation, which would demonstrate and possibly strengthen the long-term sustainability of this concept.

Author Contributions: Conceptualization, A.B., D.T.J.O. and K.B.; methodology, A.B. and K.B.; software, A.B.; validation, A.B. and K.B.; formal analysis, A.B.; investigation, A.B.; resources, K.B.; data curation, A.B.; writing-original draft preparation, A.B.; writing-review and editing, A.B., D.T.J.O. and K.B.; visualization, A.B. and K.B.; supervision, K.B.; project administration, K.B.; funding acquisition, K.B. All authors have read and agreed to the published version of the manuscript.

Funding: This research was supported by Science Foundation Ireland (SFI) through MaREI, the SFI Centre for Energy, Climate, and Marine Research and DePuy Ireland Unlimited Company on a co-funded grant agreement (SFI Targeted Project Agreement Reference No. 12/RC/2302) and the Article Processing Charge (APC) was funded by SFI.

Institutional Review Board Statement: Not applicable.

Informed Consent Statement: Not applicable.

Data Availability Statement: Data available upon request.

Conflicts of Interest: The authors declare no conflict of interest.

\section{Appendix A}

Table A1. Overview of events where the grid frequency dropped below $49.75 \mathrm{~Hz}$ during the years 2019 and 2020.

\begin{tabular}{|c|c|c|c|c|c|c|c|}
\hline$\#$ & $\begin{array}{c}\text { Date } \\
\text { (dd/mmm/yy) }\end{array}$ & $\begin{array}{l}\text { Start Time } \\
\text { (hh:mm:ss) }\end{array}$ & $\begin{array}{l}\text { Duration } \\
\text { (s) }\end{array}$ & $\begin{array}{l}\text { Trigger Frequency } \\
(\mathbf{H z})\end{array}$ & $\begin{array}{l}\text { Frequency Range } \\
\qquad(\mathrm{Hz})\end{array}$ & $\begin{array}{l}\text { Frequency } \\
\text { Event }\end{array}$ & AHU ON \\
\hline 1 & 4/January/2019 & 05:57:09 & 2 & 49.714 & $49.714-49.719$ & $\mathrm{~N}$ & $\mathrm{~N}$ \\
\hline 2 & 22/January/2019 & $20: 23: 26$ & 7 & 49.718 & $49.616-49.737$ & $\mathrm{Y}$ & $\mathrm{N}$ \\
\hline 3 & 22/January/2019 & $20: 23: 46$ & 3 & 49.746 & $49.746-49.746$ & $\mathrm{~N}$ & $\mathrm{~N}$ \\
\hline 4 & 26/January/2019 & $11: 25: 08$ & 1 & 49.727 & " & $\mathrm{N}$ & $\mathrm{Y}$ \\
\hline 5 & 2/March/2019 & $00: 13: 02$ & 3 & 49.735 & $49.635-49.735$ & $\mathrm{Y}$ & $\mathrm{N}$ \\
\hline 6 & 3/March/2019 & $06: 12: 59$ & 111 & 49.703 & $49.662-49.749$ & $\mathrm{Y}$ & $\mathrm{Y}$ \\
\hline 7 & 20/March/2019 & $16: 46: 16$ & 4 & 49.672 & $49.574-49.706$ & $\mathrm{Y}$ & $\mathrm{Y}$ \\
\hline 8 & 2/April/2019 & $13: 35: 46$ & 1 & 49.748 & “ & $\mathrm{N}$ & $\mathrm{Y}$ \\
\hline 9 & 2/April/2019 & $17: 43: 43$ & 2 & 49.743 & $49.742-49.743$ & $\mathrm{~N}$ & $\mathrm{Y}$ \\
\hline 10 & 24/April/2019 & $15: 21: 07$ & 5 & 49.702 & $49.608-49.711$ & $\mathrm{Y}$ & $\mathrm{Y}$ \\
\hline
\end{tabular}


Table A1. Cont.

\begin{tabular}{|c|c|c|c|c|c|c|c|}
\hline$\#$ & $\begin{array}{c}\text { Date } \\
(\mathrm{dd} / \mathrm{mmm} / \mathrm{yy})\end{array}$ & $\begin{array}{l}\text { Start Time } \\
\text { (hh:mm:ss) }\end{array}$ & $\begin{array}{c}\text { Duration } \\
\text { (s) }\end{array}$ & $\begin{array}{l}\text { Trigger Frequency } \\
(\mathbf{H z})\end{array}$ & $\begin{array}{l}\text { Frequency Range } \\
(\mathbf{H z})\end{array}$ & $\begin{array}{c}\text { Frequency } \\
\text { Event }\end{array}$ & AHU ON \\
\hline 11 & 8/May/2019 & 09:14:23 & 7 & 49.655 & $49.576-49.721$ & $\mathrm{Y}$ & $\mathrm{Y}$ \\
\hline 12 & 20/May/2019 & $14: 54: 12$ & 226 & 49.743 & $49.542-49.749$ & $\mathrm{Y}$ & $\mathrm{Y}$ \\
\hline 13 & 20/May/2019 & $15: 24: 52$ & 6 & 49.725 & " & $\mathrm{N}$ & Y \\
\hline 14 & 11/July/2019 & $07: 53: 37$ & 5 & 49.696 & $49.632-49.743$ & $\mathrm{Y}$ & Y \\
\hline 15 & 24/July/2019 & 15:50:09 & 1 & 49.744 & " & $\mathrm{N}$ & $\mathrm{Y}$ \\
\hline 16 & 24/July/2019 & $20: 52: 11$ & 2 & 49.730 & $49.729-49.732$ & $\mathrm{~N}$ & $\mathrm{~N}$ \\
\hline 17 & 7/October/2019 & $08: 14: 21$ & 70 & 49.735 & $49.703-49.748$ & $\mathrm{~N}$ & $\mathrm{Y}$ \\
\hline 18 & 7/October/2019 & $08: 15: 44$ & 2 & 49.749 & $49.748-49.749$ & $\mathrm{~N}$ & Y \\
\hline 19 & 7/October/2019 & $08: 15: 54$ & 12 & 49.746 & $49.742-49.748$ & $\mathrm{~N}$ & $\mathrm{Y}$ \\
\hline 20 & 7/October/2019 & 08:16:10 & 4 & 49.748 & $49.747-49.748$ & $\mathrm{~N}$ & $\mathrm{Y}$ \\
\hline 21 & 7/October/2019 & $08: 16: 17$ & 6 & 49.748 & $49.742-49.749$ & $\mathrm{~N}$ & $\mathrm{Y}$ \\
\hline 22 & 7/October/2019 & $08: 16: 41$ & 2 & 49.748 & $49.748-49.749$ & $\mathrm{~N}$ & Y \\
\hline 23 & 31/October/2019 & $02: 06: 36$ & 2 & 49.693 & $49.693-49.697$ & Y & $\mathrm{N}$ \\
\hline 24 & 25/November/2019 & 21:11:47 & 2 & 49.748 & $49.741-49.748$ & $\mathrm{~N}$ & $\mathrm{~N}$ \\
\hline 25 & 26/November/2019 & 07:39:30 & 1 & 49.721 & “ & $\mathrm{N}$ & Y \\
\hline 26 & 17/January/2020 & $18: 24: 50$ & 5 & 49.655 & $49.615-49.703$ & $\mathrm{Y}$ & $\mathrm{N}$ \\
\hline 27 & 31/January/2020 & 13:03:34 & 2 & 49.714 & $49.714-49.749$ & $\mathrm{~N}$ & $\mathrm{Y}$ \\
\hline 28 & 7/February/2020 & 10:37:06 & 2 & 49.737 & $49.720-49.737$ & $\mathrm{~N}$ & $\mathrm{Y}$ \\
\hline 29 & 25/March/2020 & 11:17:05 & 5 & 49.747 & $49.747-49.747$ & $\mathrm{~N}$ & $\mathrm{Y}$ \\
\hline 30 & 7/April/2020 & 21:04:05 & 5 & 49.747 & $49.747-49.747$ & $\mathrm{~N}$ & $\mathrm{~N}$ \\
\hline 31 & 12/May/2020 & 01:17:05 & 5 & 49.738 & $49.738-49.738$ & $\mathrm{~N}$ & $\mathrm{~N}$ \\
\hline 32 & $18 /$ June/2020 & 19:07:55 & 10 & 49.593 & $49.593-49.671$ & $\mathrm{Y}$ & $\mathrm{N}$ \\
\hline 33 & 1/July/2020 & $15: 29: 25$ & 5 & 49.734 & $49.734-49.734$ & $\mathrm{~N}$ & Y \\
\hline 34 & 19/July/2020 & $06: 26: 35$ & 45 & 49.599 & $49.599-49.748$ & $\mathrm{Y}$ & $\mathrm{Y}$ \\
\hline 35 & 21/August/2020 & $15: 20: 15$ & 5 & 49.708 & $49.708-49.708$ & $\mathrm{~N}$ & $\mathrm{Y}$ \\
\hline 36 & 23/September/2020 & 11:02:15 & 5 & 49.531 & $49.531-49.531$ & $\mathrm{Y}$ & Y \\
\hline
\end{tabular}

\section{References}

1. Sustainable Energy Authority of Ireland. Renewable Energy in Ireland; SEAI: Dublin, Ireland, 2020.

2. Sustainable Energy Authority of Ireland. Energy in Ireland-2020 Report; SEAI: Dublin, Ireland, 2020.

3. Carlini, E.M.; Schroeder, R.; Birkebæk, J.M.; Massaro, F. EU transition in power sector How RES affects the design and operations of transmission power systems. Electr. Power Syst. Res. 2019, 169, 74-91. [CrossRef]

4. EirGrid Group. Industry Guide to the I-SEM; EirGrid: Dublin, Ireland, 2017.

5. EirGrid Group. Frequency: All Island. Available online: http://smartgriddashboard.eirgrid.com/\#all/frequency (accessed on 9 October 2021).

6. Raidió Teilifís Éireann. Tánaiste "Reasonably Confident" There Will Not Be Blackouts This Winter; RTÉ News: Dublin, Ireland, 2021.

7. Newbery, D. Tales of two islands-Lessons for EU energy policy from electricity market reforms in Britain and Ireland. Energy Policy 2017, 105, 597-607. [CrossRef]

8. Commission for Regulation of Utilities (CRU). Electricity Security of Supply Report 2018; CRU: Dublin, Ireland, 2018.

9. EirGrid; SONI. DS3 System Services Protocol_Regulated Arrangements; EirGrid: Dublin, Ireland, 2019.

10. Gu, C.; Zhang, Y.; Wang, J.; Li, Q. Joint planning of electrical storage and gas storage in power-gas distribution network considering high-penetration electric vehicle and gas vehicle. Appl. Energy 2021, 301, 117447. [CrossRef]

11. Hooshmand, R.A.; Nosratabadi, S.M.; Gholipour, E. Event-based scheduling of industrial technical virtual power plant considering wind and market prices stochastic behaviors-A case study in Iran. J. Clean. Prod. 2018, 172, 1748-1764. [CrossRef]

12. EirGrid; SONI. All-Island Generation Capacity Statement 2020-2029; EirGrid: Dublin, Ireland, 2020.

13. EirGrid. Tomorrow's Energy Scenarios 2019 Ireland; EirGrid: Dublin, Ireland, 2019.

14. Kiptoo, M.K.; Adewuyi, O.B.; Lotfy, M.E.; Ibrahimi, A.M.; Senjyu, T. Harnessing demand-side management benefit towards achieving a 100\% renewable energy microgrid. Energy Rep. 2020, 6, 680-685. [CrossRef]

15. Oikonomou, K.; Parvania, M.; Khatami, R. Coordinated deliverable energy flexibility and regulation capacity of distribution networks. Int. J. Electr. Power Energy Syst. 2020, 123, 106219. [CrossRef]

16. Brem, A.; Adrita, M.M.; O'Sullivan, D.T.J.; Bruton, K. Industrial smart and micro grid systems-A systematic mapping study. J. Clean. Prod. 2020, 244, 118828. [CrossRef]

17. Sustainable Energy Authority of Ireland. Large Industry Energy Network. Available online: https://www.seai.ie/energy-inbusiness/lien/ (accessed on 11 October 2021).

18. Siano, P. Demand response and smart grids-A survey. Renew. Sustain. Energy Rev. 2014, 30, 461-478. [CrossRef] 
19. Thavlov, A.; Bindner, H.W. Utilization of Flexible Demand in a Virtual Power Plant Set-Up. IEEE Trans. Smart Grid 2015, 6, 640-647. [CrossRef]

20. Michaud, G. Deploying solar energy with community choice aggregation: A carbon fee model. Electr. J. 2018, 31, 32-38. [CrossRef]

21. Rogers, A.P.; Rasmussen, B.P. Opportunities for consumer-driven load shifting in commercial and industrial buildings. Sustain. Energy Grids Netw. 2018, 16, 243-258. [CrossRef]

22. Heydt, G.T. Implementation of smart grid objectives among distribution system residential, commercial, and industrial loads. In Proceedings of the 2016 North American Power Symposium (NAPS), Denver, CO, USA, 18-20 September 2016; IEEE: Piscataway, NJ, USA, 2016; pp. 1-6.

23. Zhang, Q.; Grossmann, I.E. Enterprise-wide optimization for industrial demand side management: Fundamentals, advances, and perspectives. Chem. Eng. Res. Des. 2016, 116, 114-131. [CrossRef]

24. Naderi, M.; Bahramara, S.; Khayat, Y.; Bevrani, H. Optimal planning in a developing industrial microgrid with sensitive loads. Energy Rep. 2017, 3, 124-134. [CrossRef]

25. Royapoor, M.; Pazhoohesh, M.; Davison, P.J.; Patsios, C.; Walker, S. Building as a virtual power plant, magnitude and persistence of deferrable loads and human comfort implications. Energy Build. 2020, 213, 109794. [CrossRef]

26. Rodríguez-García, J.; Álvarez-Bel, C.; Carbonell-Carretero, J.-F.F.; Escrivá-Escrivá, G.; Calpe-Esteve, C. Design and validation of a methodology for standardizing prequalification of industrial demand response resources. Electr. Power Syst. Res. 2018, 164, 220-229. [CrossRef]

27. Viotas Fully Managed Demand Response. Available online: https://viotas.com/solutions/solutions-demand-response/ (accessed on 8 November 2021).

28. Grid Beyond. Working Together. Available online: https://gridbeyond.com/ (accessed on 8 November 2021).

29. Pechmann, A.; Shrouf, F.; Chonin, M.; Steenhusen, N. Load-shifting potential at SMEs manufacturing sites: A methodology and case study. Renew. Sustain. Energy Rev. 2017, 78, 431-438. [CrossRef]

30. Choobineh, M.; Mohagheghi, S. A multi-objective optimization framework for energy and asset management in an industrial Microgrid. J. Clean. Prod. 2016, 139, 1326-1338. [CrossRef]

31. Brem, A.; Cusack, D.Ó.; Adrita, M.M.; O’Sullivan, D.T.J.; Bruton, K. How do companies certified to ISO 50001 and ISO 14001 perform in LEED and BREEAM assessments? Energy Effic. 2020, 13, 751-766. [CrossRef]

32. Maussion, P. Design of Experiments in electrical engineering: Applications in control and modeling. In Proceedings of the 2017 IEEE Workshop on Electrical Machines Design, Control and Diagnosis (WEMDCD), Nottingham, UK, 20-21 April 2017; IEEE: Piscataway, NJ, USA, 2017; pp. 179-186.

33. Miki, K.; Saito, A.; Nakashima, T.; Murakami, Y.; Kimura, T.; Nishibuchi, I.; Nagata, Y. Evaluation of optimization workflow using design of experiment (DoE) for various field configurations in volumetric-modulated arc therapy. Phys. Med. 2018, 54, 34-41. [CrossRef] [PubMed]

34. Fukuda, I.M.; Pinto, C.F.F.; Moreira, C.D.S.; Saviano, A.M.; Lourenço, F.R. Design of Experiments (DoE) applied to Pharmaceutical and Analytical Quality by Design (QbD). Braz. J. Pharm. Sci. 2018, 54, 1-16. [CrossRef]

35. Bahraminasab, M.; Jahan, A.; Sahari, B.; Arumugam, M.; Shamsborhan, M.; Hassan, M.R. Using Design of Experiments Methods for Assessing Peak Contact Pressure to Material Properties of Soft Tissue in Human Knee. J. Med. Eng. 2013, 2013, 891759. [CrossRef]

36. Griffiths, C.A.; Howarth, J.; De Almeida-Rowbotham, G.; Rees, A.; Kerton, R. A design of experiments approach for the optimisation of energy and waste during the production of parts manufactured by 3D printing. J. Clean. Prod. 2016, 139, 74-85. [CrossRef]

37. International Organization for Standardization. ISO 31000 Risk Management_Guidelines; ISO: Geneva, Switzerland, 2018.

38. International Organization for Standardization. Risk Management_Risk Assessment Techniques; ISO: Dublin, Ireland, 2010.

39. Chemweno, P.; Pintelon, L.; Muchiri, P.N.; Van Horenbeek, A. Risk assessment methodologies in maintenance decision making: A review of dependability modelling approaches. Reliab. Eng. Syst. Saf. 2018, 173, 64-77. [CrossRef]

40. Passath, T.; Mertens, K. Decision Making in Lean Smart Maintenance: Criticality Analysis as a Support Tool. IFAC-PapersOnLine 2019, 52, 364-369. [CrossRef]

41. Jaderi, F.; Ibrahim, Z.Z.; Zahiri, M.R. Criticality analysis of petrochemical assets using risk based maintenance and the fuzzy inference system. Process Saf. Environ. Prot. 2019, 121, 312-325. [CrossRef]

42. Jaderi, F.; Ibrahim, Z.Z.; Jaafarzadeh, N.; Abdullah, R.; Yavari, A.R.; Shamsudin, M.N.; Nabavi, S.M.B. Criticality analysis using risk assessment-based maintenance of a petrochemical company. Pol. J. Environ. Stud. 2014, 23, $2033-2037$.

43. Martínez-Galán, P.; Gómez, J.F.; Crespo, A.; Guillén, A.; de la Fuente, A.; Candón, E. Criticality Analysis for Network Utilities Asset Management. IFAC-PapersOnLine 2019, 52, 2074-2079. [CrossRef]

44. Melani, A.H.A.; Murad, C.A.; Caminada Netto, A.; de Souza, G.F.M.; Nabeta, S.I. Criticality-based maintenance of a coal-fired power plant. Energy 2018, 147, 767-781. [CrossRef]

45. SIEMENS. Totally Integrated Power —Industrial Plants_Applications for Electric Power Distribution; SIEMENS: Munich, Germany, 2021.

46. ABB. ABB Delivers Cost-Efficient Load-Shedding Solution to Glencane Bioenergia. Available online: https://new.abb.com/ news / detail/53056/abb-delivers-cost-efficient-load-shedding-solution-to-glencane-bioenergia (accessed on 22 November 2021).

47. Blake, S.T.; O'Sullivan, D.T.J. Optimization of Distributed Energy Resources in an Industrial Microgrid. Procedia CIRP 2018, 67, 104-109. [CrossRef] 
48. Dababneh, F.; Li, L.; Sun, Z. Peak power demand reduction for combined manufacturing and HVAC system considering heat transfer characteristics. Int. J. Prod. Econ. 2016, 177, 44-52. [CrossRef]

49. Yin, R.; Kara, E.C.; Li, Y.; DeForest, N.; Wang, K.; Yong, T.; Stadler, M. Quantifying flexibility of commercial and residential loads for demand response using setpoint changes. Appl. Energy 2016, 177, 149-164. [CrossRef]

50. Chen, Y.; Chen, Z.; Xu, P.; Li, W.; Sha, H.; Yang, Z.; Li, G.; Hu, C. Quantification of electricity flexibility in demand response: Office building case study. Energy 2019, 188, 116054. [CrossRef]

51. Amin, U.; Hossain, M.J.; Fernandez, E. Optimal price based control of HVAC systems in multizone office buildings for demand response. J. Clean. Prod. 2020, 270, 122059. [CrossRef]

52. Brem, A.; Bruton, K.; O'Sullivan, P.D. Assessing the Risk to Indoor Thermal Environments on Industrial Sites Offering AHU Capacity for Demand Response. Energies 2021, 14, 6261. [CrossRef]

53. Willumsen, P.; Oehmen, J.; Stingl, V.; Geraldi, J. Value creation through project risk management. Int. J. Proj. Manag. 2019, 37, 731-749. [CrossRef]

54. Leimeister, M.; Kolios, A. A review of reliability-based methods for risk analysis and their application in the offshore wind industry. Renew. Sustain. Energy Rev. 2018, 91, 1065-1076. [CrossRef]

55. EirGrid; SONI. DS3 System Services Protocol—Regulated Arrangements 3.0; EirGrid: Dublin, Ireland, 2020.

56. Schoen, L.J.; Alspach, P.F.; Arens, E.A.; Aynsley, R.M.; Bean, R.; Eddy, J.; Int-Hout, D.; Khalil, E.E.; Simmonds, P.; Stoops, J.L.; et al. ANSI/ASHRAE Standard 55-2013-Thermal Environmental Conditions for Human Occupancy; ASHRAE: Peachtree Corners, GA, USA, 2013.

57. Electricity Supply Board. Generation Asset Map. Available online: https:/ / esb.ie/our-businesses/generation-energy-tradingnew/generation-asset-map (accessed on 15 September 2021).

58. Environmental Protection Agency (EPA). Waste License; EPA: Washington, DC, USA, 2011.

59. Statkraft Ireland Ltd. Batteries. Available online: https://www.statkraft.ie/what-we-do/Grid-Services-and-Batteries/ (accessed on 15 September 2021).

60. EirGrid; SONI. DS3 System Services Statement of Payments; EirGrid: Dublin, Ireland, 2018.

61. Baxtel. Republic of Ireland Data Center Market. Available online: https://baxtel.com/data-center/republic-of-ireland (accessed on 4 October 2021).

62. EirGrid; SONI. DS3 System Services Scalar Design—Recommendations Paper; EirGrid: Dublin, Ireland, 2017. 